\title{
Tabular iceberg collisions within the coastal regime
}

\author{
Douglas R. MACAYEAL, ${ }^{1}$ Marianne H. OKAL, ${ }^{1 *}$ Jonathan E. THOM, ${ }^{2}$ \\ Kelly M. BRUNT, ${ }^{1}$ Young-Jin KIM, ${ }^{1}$ Andrew K. BLISS ${ }^{3}$ \\ ${ }^{1}$ Department of Geographical Sciences, University of Chicago, 5734 South Ellis Avenue, Chicago, Illinois 60637, USA \\ E-mail: drm7@midway.uchicago.edu \\ ${ }^{2}$ Space Science and Engineering Center, University of Wisconsin-Madison, 1225 West Dayton Street, Madison, \\ Wisconsin 53706, USA \\ ${ }^{3}$ Department of Geography, University of California Berkeley, 507 McCone Hall, Berkeley, California 94720-4740, USA
}

\begin{abstract}
During 2000-07, five giant icebergs (B15A, B15J, B15K, C16 and C25) adrift in the southwestern Ross Sea, Antarctica, were instrumented with global positioning system (GPS) receivers and other instruments to monitor their behavior in the near-coastal environment. The measurements show that collision processes can strongly influence iceberg behavior and delay their progress in drifting to the open ocean. Collisions appear to have been a dominant control on the movement of B15A, the largest of the icebergs, during the 4-year period it gyrated within the limited confines of Ross Island, the fixed Ross Ice Shelf and grounded C16. Iceberg interactions in the near-coastal regime are largely driven by ocean tidal effects which determine the magnitude of forces generated during collision and break-up events. Estimates of forces derived from the observed drift trajectories during the iceberg-collisioninduced calving of iceberg C19 from the Ross Ice Shelf, during the iceberg-induced break-off of the tip of the Drygalski Ice Tongue and the break-up of B15A provide a crude estimate of the stress scale involved in iceberg calving. Considering the total area the vertical face of new rifts created in the calving or break-up process, and not accounting for local stress amplification near rift tips, this estimated stress scale is $10^{4} \mathrm{~Pa}$.
\end{abstract}

\section{INTRODUCTION}

Since James Cook's second voyage of discovery (1772-75), when large tabular icebergs originating from a south-polar continent were seen and initially documented (Herdman, 1959; Glaciological Society, 1962), icebergs have been a focus of scientific inquiry, attempting to understand their relationship to, and impact on, environmental and ecological systems of the high southern latitudes. Efforts to study these vagabonds of the Southern Ocean have been difficult, however, because calving of large icebergs (i.e. exceeding an area of $500 \mathrm{~km}^{2}$ ) is episodic, unpredictable and occurs on a timescale of 10-100 years. Erratic iceberg drift also makes rendezvous with scientific parties impractical.

To expand the body of surface-based observations of large tabular icebergs, we undertook a field-observation campaign in early 2001 to study a series of giant icebergs, ranging from 500 to $>3000 \mathrm{~km}^{2}$, that had been calved from the Ross Ice Shelf since March 2000. This campaign was opportunistic, being motivated in large part by the presence of the icebergs in the vicinity of the US research base on Ross Island, Antarctica. The scientific activity consisted of occupying icebergs B15A, C16, B15J, B15K and C25 (Fig. 1) to install automatic weather stations (AWS), global positioning system (GPS) receivers and other instruments configured to monitor iceberg movement and surface conditions.

The purpose of our field campaign was to determine the effects of iceberg collisions with various objects of the coastal environment, such as ice-shelf ice fronts, ice tongues, ice-free coastlines, shoals and other icebergs. Collisions in the coastal zone were of particular interest because they are

*Present address: UNAVCO, 6350 Nautilus Drive, Boulder, Colorado 80301-5554, USA. believed to act as a dynamic filter that reduces the size of icebergs released from Antarctica, and that allows the impact of iceberg discharge on the ocean beyond Antarctica to have greater temporal and spatial dispersion. The initial objective of the field effort was to study iceberg B15, which calved in March 2000 from the Ross Ice Shelf. Over the first 12 months of B15's lifetime, the iceberg was broken into nine pieces as a result of collisional contact with the Ross Ice Shelf ice front and was dispersed spatially with pieces becoming separated by $>1000 \mathrm{~km}$. Two of the pieces that remained close to Ross Island, B15J and B15K, were incorporated into the field effort because of their proximity to the US research station.

The most significant result of the work so far, and that which forms the subject of the present paper, is the understanding of how several of the largest icebergs released into the Ross Sea when B15 calved were unexpectedly retained in the near-coastal environment for periods up to many years. B15A was trapped in the southern Ross Sea, without ever becoming grounded, from early 2000 to late 2005. B15J, a piece of B15A that broke off in response to collisional activity in late 2003, continues to be trapped in the southwestern Ross Sea. This exemplifies the nature of the effect of the coastal environment on iceberg break-up and drift: the environmental impact of the original B15 iceberg, containing $\sim 2000 \mathrm{~km}^{3}$ of ice to eventually be discharged as meltwater, was mitigated by effects of the near-coastal environment. The observational picture presented by our data confirms that iceberg-on-ice and iceberg-on-coast collisions act as an important filter on iceberg drift, retarding it within the coastal zone. What distinguishes the present study from previous studies of iceberg motion is the coastal proximity of the instrumented icebergs studied here and importance of collisional dynamics as a control on iceberg drift in this near-coastal environment (for a review of iceberg 


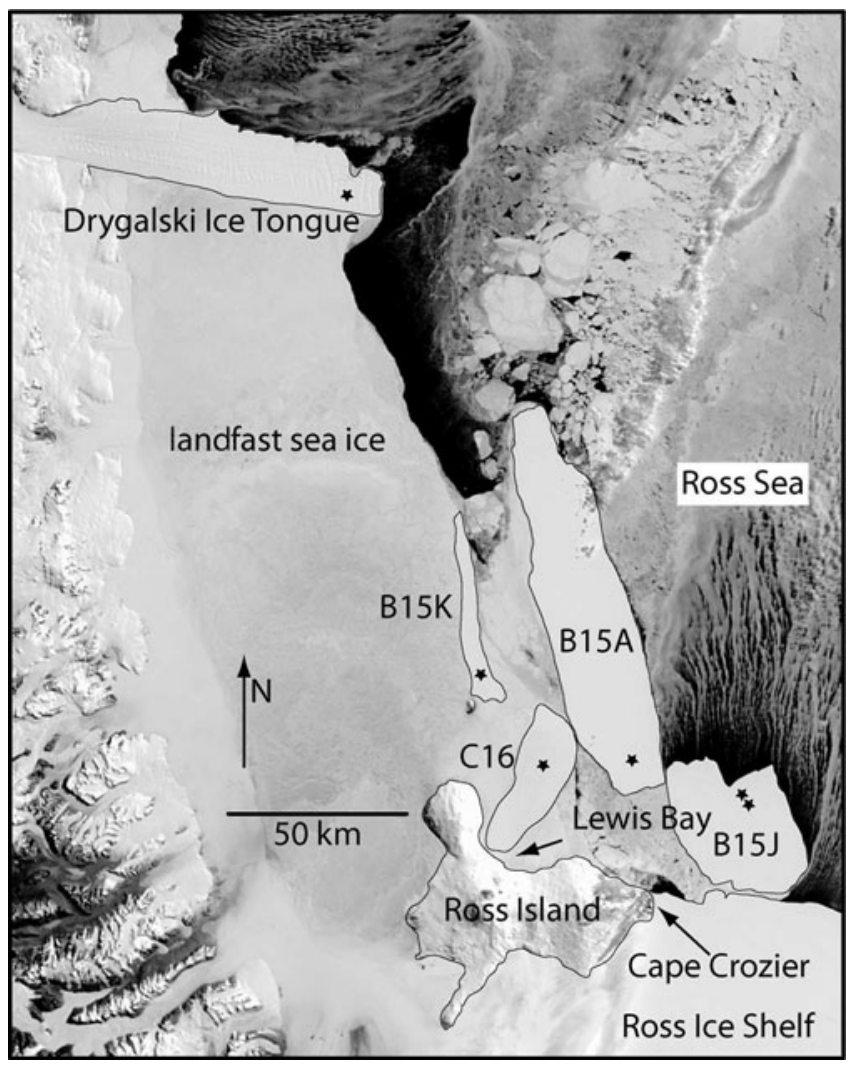

Fig. 1. MODIS (moderate-resolution imaging spectroradiometer) image of icebergs in southwestern Ross Sea, 9 November 2004, displaying a typical configuration of the icebergs under study during the time they were resident near Ross Island. Stars denote approximately where AWS equipped with GPS receivers were deployed in January 2001 (B15J), December 2001 (C16), October 2003 (B15A), November 2004 (B15K) and October 2006 (Drygalski Ice Tongue, the tip of which became iceberg C25). Among the many consequences of the icebergs' 6 year presence in the area was the development of multi-year landfast sea ice in the region between Ross Island and the Drygalski Ice Tongue. In this image, B15K and C16 are grounded and immobile. B15A and B15J are moving and colliding with each other, with iceberg C16 and with the Ross Ice Shelf and Ross Island. The effect of the group of four icebergs was to act as a natural breakwater, preventing the normal spring break-up of the landfast sea ice (Brunt and others, 2006).

motion focusing on the open-ocean environment, see, e.g., Bigg and others, 1997; Gladstone and others, 2001; Lichey and Hellmer, 2001).

\section{SUMMARY OF ICEBERG ACTIVITY}

During 2000-02, a series of nine giant icebergs were calved from the Ross (B15, B16, B17, B18, C16, C18 and C19) and Ronne (A43 and A44) Ice Shelves of Antarctica (Young, 1998, 2002a, b, 2005; Lazzara and others, 1999; Long and others, 2002; see also satellite image compilations on the web, e.g. http://polar.ocean.washington.edu/ ROSS and http://ice.ssec.wisc.edu/iceberg.php). Assuming typical ice thicknesses near the front of the Ross and Ronne Ice Shelves (250 m; see Shabtaie and Bentley, 1982; Peters and others, 2007), the combined volume of these icebergs is $\sim 10000 \mathrm{~km}^{3}$, or $\sim 9091 \mathrm{GT}\left(1 \mathrm{GT}=10^{12} \mathrm{~kg}\right)$. Plausible uncertainty in ice thicknesses at the time of calving suggests that $\pm 2000 \mathrm{~km}^{3}$, or about $\pm 1818 \mathrm{GT}$, would suffice as an estimate of uncertainty. The background calving rate applicable to years when giant tabular icebergs are not produced is estimated to be $800-1000 \mathrm{GTa}^{-1}$ (Jacobs and others, 1992; Rignot and Thomas, 2002; Silva and others, 2006; Jacka and Giles, 2007). The snow accumulation rate for the entire Antarctic ice sheet (grounded and floating portions) is estimated to be $\sim 2300 \mathrm{GTa}^{-1}$ (Bentley and Giovinetto, 1991; Vaughan and others, 1999). The above estimates suggest that the nine giant icebergs calved in the 2000-02 time frame represent 7-14 times the normal background calving rate from Antarctica, and 3-5 times the annual snow accumulation for the entire continent.

Iceberg B15, the progenitor of the icebergs studied in our field campaign, calved from the eastern side of the Ross Ice Shelf ice front on 21 March 2000, and remained close to its position of origin for $\sim 4$ weeks (two spring-neap tidal cycles) where it collided repeatedly with the Ross Ice Shelf. During one of the collisions against the ice shelf east of the Bay of Whales, on approximately 7 April 2000, B15 caused $\mathrm{B} 17$ and B18 to calve from the Ross Ice Shelf. This process of iceberg calving, originally proposed by Swithinbank and others (1977), was witnessed at least four more times in the 2000-06 time frame, with the calving of C16 (September 2000), C18 and C19 (11 May 2002), an unnamed iceberg (derived from the Drygalski Ice Tongue in January 2005) and C25 (29 March 2006), all resulting from collisions of icebergs descended from B15 with the Ross Ice Shelf or the Drygalski Ice Tongue (Fig. 1).

In early May 2000, after drifting west along the ice front for several months, B15 broke in half, producing B15A and B15B. In August and September 2000, B15B moved north from the ice front by jackknifing with B15A which was in contact with the ice front. Eventually B15B exited the Ross Sea by following the continental shelf edge to the west, breaking up as it passed Cape Adare in April 2001 (Martin and others, 2007). In the months immediately following the B15A/B split, B15A continued to drift west along the ice front, and collided with the ice front at its most extreme western end to produce iceberg $\mathrm{C} 16$ in late September 2000. Iceberg C16, prior to calving, had been the most advanced, northerly portion of the Ross Ice Shelf.

In early 2001, B15A and C16 drifted into the region just north of Ross Island, where they were to remain until early 2005 and early 2006, respectively. Iceberg C16 was the only iceberg that grounded during this lengthy period, and was pinned by a shoal in the area between Lewis Bay and Beaufort Island (i.e. the small island immediately south of B15K on Fig. 1). B15A moved back and forth for the 4 year period it remained near Ross Island, often colliding with C16 to the west, Ross Island (Cape Crozier) to the south and the Ross Ice Shelf to the east. After 2 years of thrashing within the confines imposed by these features, B15A split into three icebergs, B15A, B15J and B15K, in late 2003, and these three icebergs remained in the area for the following year.

In November 2004, B15A drifted north from the immediate confines of Ross Island, collided with the Drygalski Ice Tongue (which produced an unnamed iceberg off the tip) and exited the Ross Sea in late October 2005, following a westward drift trajectory along the Oates Coast of East Antarctica. Iceberg C16 remained aground just north of Ross Island until 30 January 2006, at which point it floated free of the seabed and began to drift along the Scott and Borchgrevink Coast of the western Ross Sea. On 29 March 2006, C16 ran into the tip of the Drygalski Ice Tongue and caused the calving of iceberg C25. The occasion of C16's 
remobilization from a 4 year period of being aground appears to have happened in response to its thinning by basal melting. Iceberg B15J has remained the longest in the region of Ross Island. After splitting from B15A in October 2003, B15J spent 4 years in the vicinity of Cape Crozier or in the area between Ross Island and Franklin Island (Fig. 1). As of January 2008, B15J has moved north of the Drygalski Ice Tongue and appears on its way out of the Ross Sea.

\section{Field methods and instrumentation}

Field activity began on 25 January 2001 using the US Coast Guard cutter Polar Sea equipped with a detachment of US Coast Guard helicopters to land field parties on iceberg B15A. These field parties deployed the first of a series of AWS, GPS, seismometer and automated camera instrument packages deployed on B15A and four other icebergs (C16, B15J, B15K and C25) through the following 5 years. After the initial January 2001 field deployments, logistics shifted from icebreaker to helicopter and fixed-wing aircraft operating from the US research base, McMurdo Station, because of the close proximity of the icebergs to Ross Island. Data from these instruments (except for the seismometers) were transmitted by satellite. The slow, but extremely reliable Argos satellite data-transfer system was used for AWS and GPS data.

Instruments deployed on the icebergs were designed for year-round operation and involved sensors, data loggers and power-supply systems that are in common use in Antarctica (e.g. http://amrc.ssec.wisc.edu/aws.html). Weather instruments were purchased from Campbell Scientific Inc. and were operated by CR10x data loggers running on a $10 \mathrm{~s}$ table 1 interval, with average results for pressure, temperature and wind computed every $20 \mathrm{~min}$. The Campbell Scientific Inc. weather sensors were: R.M. Young RTD temperature probe with solar shield, HMP45C temperature and relative humidity probe with solar shield, Vaisala PTB101B barometer, SR50 ultrasonic snow-distance sensor, SP-LITE solar radiation sensor and R.M. Young wind monitor. The temperature measurements were made without active aspiration of the solar shield, because of power-supply constraints. Digital compass and GPS readings were taken every 20 min using a Campbell Scientific Inc. SDM-SIO4 serial interface for the CR10x that was programmed to read NEMA 802.3 output sentences. The GPS receivers were either Trimble SV8, Garmin GPS36 or Garmin GPS17hvs models, which all are relatively low-power-consuming sensors that lack keyboard and displays. Digital compasses were either KVH C100 or AOSItilt models.

\section{ICEBERG COLLISIONS}

During the 6 year study period, hundreds of collisions between the icebergs, and between icebergs and coastal features, were recorded by the GPS receivers and observed with ground-based photography, aerial photography and satellite imagery (see the website database of satellite imagery maintained by the University of Wisconsin at http://ice.ssec.wisc.edu/iceberg.php). Collisions between $\mathrm{B} 15 \mathrm{~A}$ or $\mathrm{B} 15 \mathrm{~J}$ and grounded $\mathrm{C} 16$ were the most common events observed. The above-sea-level damage features caused by these collisions, referred to as 'push mounds' (a term coined by B. Kerman, personal communication, 2001), are shown in Figure 2. These mounds of broken firn could sometimes reach elevations of $25-50 \mathrm{~m}$ above the

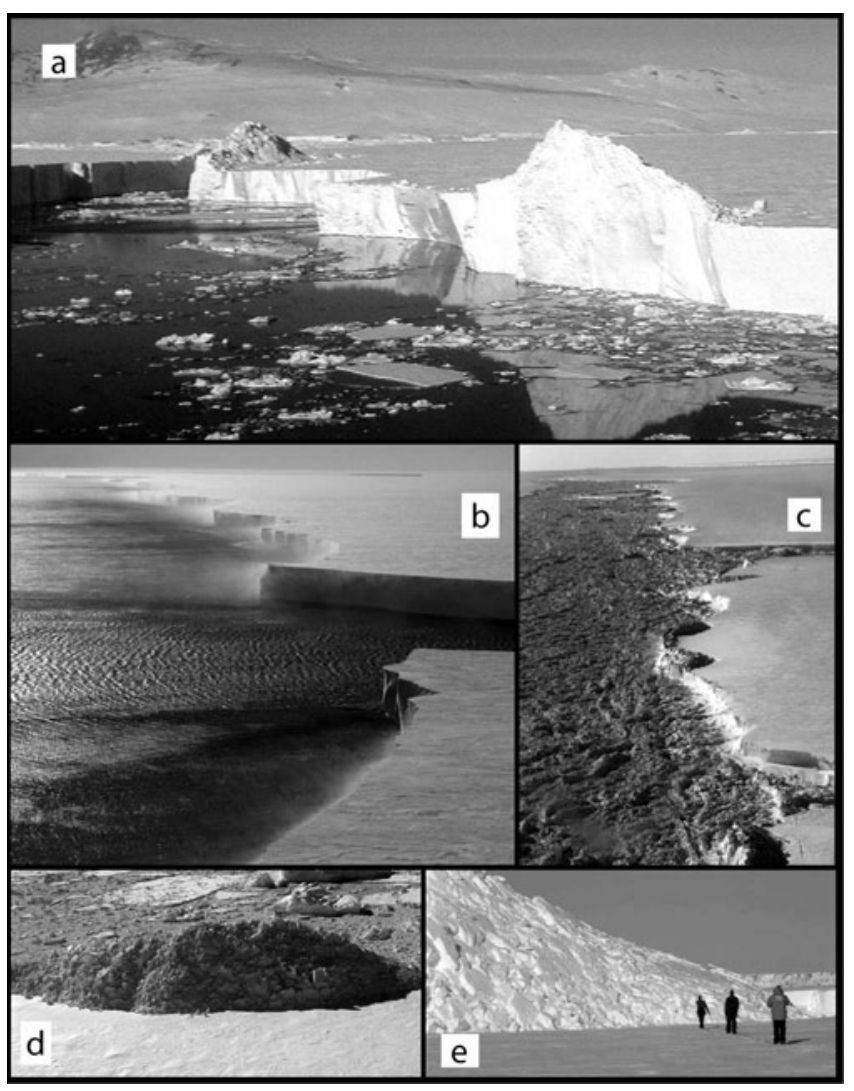

Fig. 2. Collision damage along iceberg edges. (a) Push mounds on C16 (right, $25 \mathrm{~m}$ high from the water level) with B15's edge visible on the left and Ross Island (Mount Terror) in the background. (b) The edge of B15A in January 2001, before it collided with C16. (c) Aftercollision image of the same C16-facing edge of B15A in October 2003. (d) Push mound at the northeastern corner of C16 in January 2004. (e) Ground-eye view of push mound shown in (d). Push mounds represent the above-waterline damage features along an iceberg edge that results from iceberg collisions with other icebergs. Push mounds typically break off the edge of the iceberg in a matter of days to weeks.

surrounding iceberg surface. The extent of edge damage to the icebergs below the water surface is unknown. Icebergs B15A and B15J often collided with the coast of Ross Island. These interactions were of greatest interest to biologists studying penguin rookeries in the area (e.g. Ainley and others, 2004, 2006; Shepherd and others, 2005), because pieces of the icebergs would often become stranded on the beach, or in shallow water close to the beach, and present significant barriers to penguins attempting to walk or swim to their colonies. Stranded iceberg pieces that had an impact on the Adélie penguin colony at Cape Crozier forming the eastern end of Ross Island are shown in Figure 3.

\section{Collision kinematics}

The overall picture of iceberg collisions can best be illustrated by considering two limited examples of motions recorded by the iceberg instrumentation. While extremely subtle, the motions of $\mathrm{C} 16$ across the seabed shoal on which it was grounded prior to January 2006 were of special diagnostic interest, and serve as the first example. These motions, shown in Figures 4-7, were studied by Okal (2005) in an effort to establish both the forces associated with iceberg collisions and the forces required to push grounded 


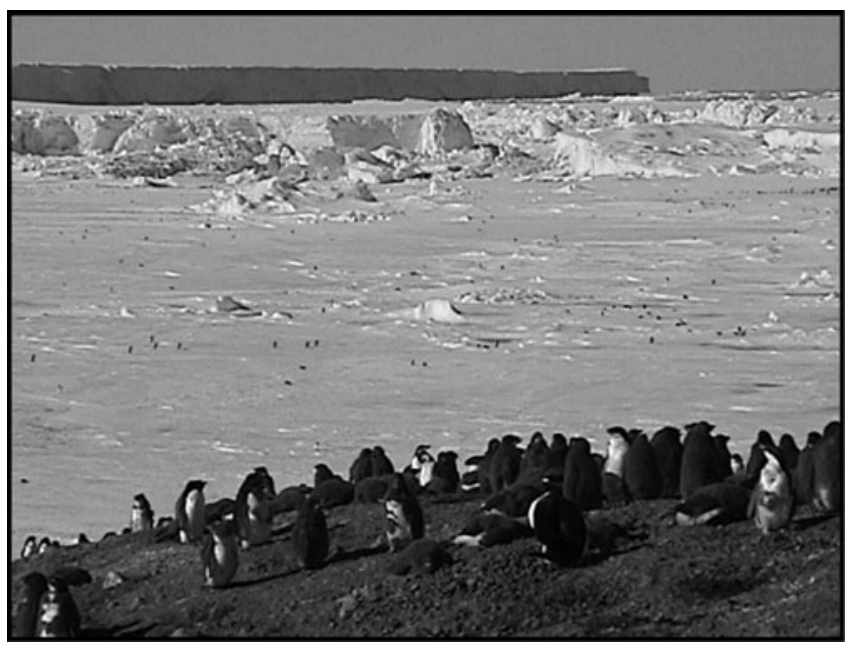

Fig. 3. Once push mounds (Fig. 2) break off, they become ice rubble that floats on the sea surface or is pushed ashore along the coast of Ross Island (foreground). This rubble represented a significant challenge to the Adélie penguin colony at Cape Crozier (eastern end of Ross Island near intersection with front of Ross Ice Shelf, 2003; photo courtesy of D. Ainley) during the time B15 remained near Ross Island. Iceberg B15J looms in the background. Landfast sea ice is seen shoreward of stranded iceberg debris with small black objects (penguins). The 5 year presence of icebergs in the southwestern Ross Sea near various penguin colonies had a strong impact on penguin breeding and mortality (Ainley and others, 2006).

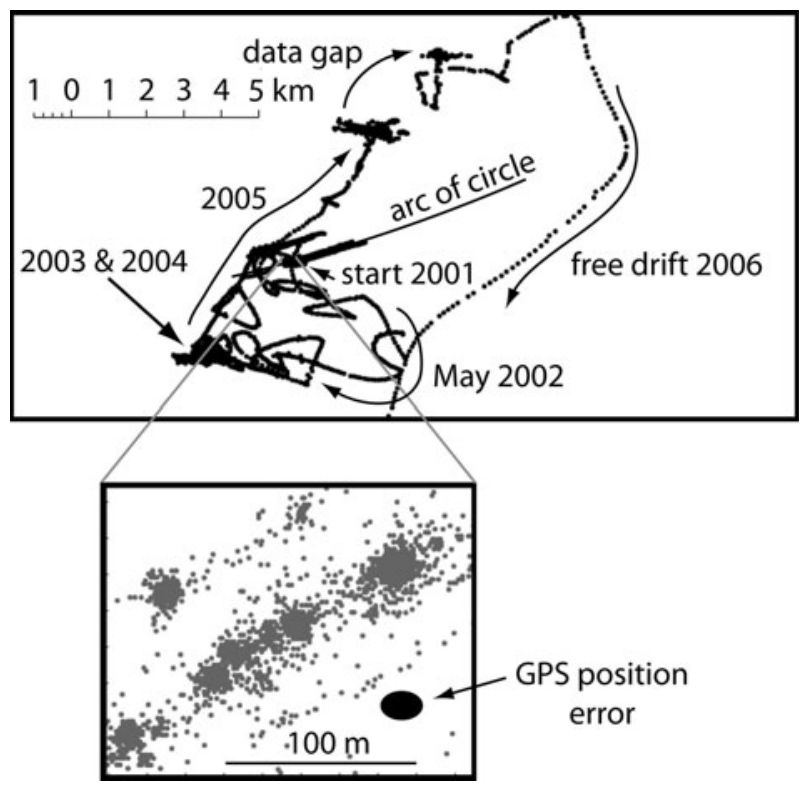

Fig. 4. GPS positions (points) of the station on C16 from December 2001 to January 2006 (Okal, 2005). The limited area $(\sim 10 \mathrm{~km}$ by $10 \mathrm{~km}$ ) within which these positions fall indicates the extent to which $\mathrm{C} 16$ was immobilized by grounding during the period prior to January 2006 (north up). The spread of GPS positions among several clusters and arcs indicates that C16 shifted horizontally numerous times during the period, by sliding across its grounding points. All of these shifts correlate with times when C16 was struck by B15A or B15J. Several of the movements during 2002 produced GPS positions that fell on arcs of circles, indicating that the iceberg was pinwheeling on a grounding point to the northwest of the AWS site. A close-up of the GPS positions (lower panel) shows that the points cluster into small ellipses representative of the measurement uncertainty of the GPS receivers (Garmin model GPS36), which is $\sim 25 \mathrm{~m}$. These ellipses are labeled time-sequentially by letters, and their sequence in time is described in Figure 5.

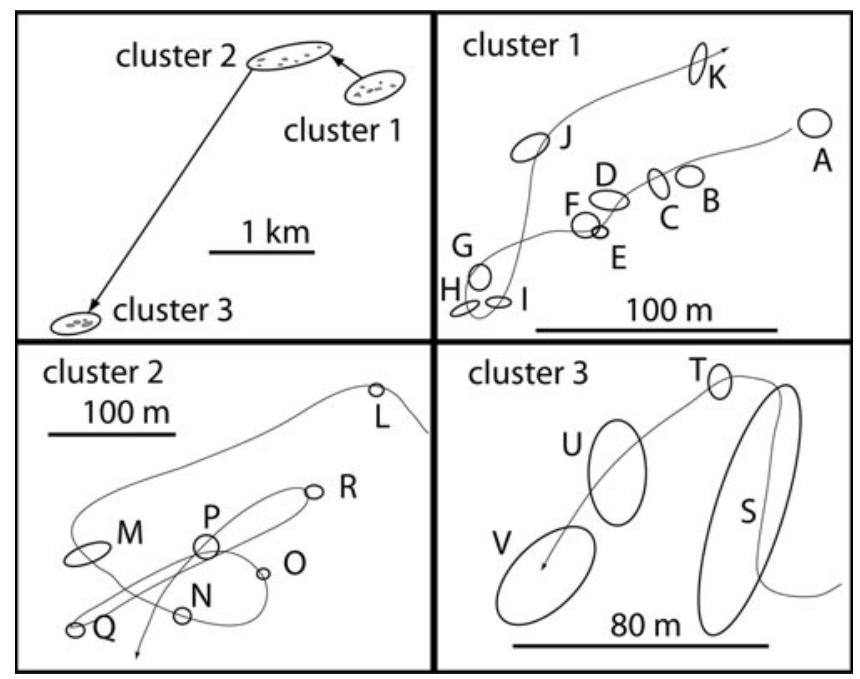

Fig. 5. Sequential summary of motions of C16's GPS position during time the C16 was grounded (north up). Letter labels refer to GPS position ellipses described in Figure 4. The purpose of sequentially labeling the ellipses according to the time period over which the GPS positions were resident within each ellipse was to investigate whether the movement from one ellipse to another (occurring over a relatively short period of time (e.g. a matter of hours)) was a result of $\mathrm{C} 16$ being struck by B15A or B15J. Analysis of the timing of shifts from one ellipse to the next, primarily by comparison with the GPS trajectories of the other icebergs, indicates that C16 was indeed pushed over its seabed pinning points by strong collision forces (Okal, 2005). These forces, estimated in Figure 12, suggest that the magnitude of stress at the contact between the seabed and C16's base is $\sim 10^{3} \mathrm{~Pa}$ when $\mathrm{C} 16$ is able to be pushed across this contact.

icebergs across the seabed on which they rest. The second example is the motion of B15A prior to the time it split into B15A and B15J on 8 October 2003. During this period, the trajectory of the AWS/GPS station on the iceberg was diagnostic of a geometric 'keyhole' within which the iceberg appeared to be stuck. This keyhole, displayed in Figure 8, was determined by the shapes of the iceberg and the various coastal features (including the edges of grounded C16).

\section{Kinematics of a grounded iceberg: C16}

A result of the constant battering of grounded iceberg C16 by icebergs B15A and B15J was the tendency for C16's GPS position data to cluster in discrete, sometimes overlapping, ellipses with length scales commensurate with the $25 \mathrm{~m}$ accuracy of the GPS receiver (see also Okal, 2005). There were more than 30 such elliptical clusters discernible in the GPS data, several of which are shown in Figures 4 and 5. Within each ellipse, the differences between GPS position points are consistent with the error range of the GPS equipment used. The iceberg is considered to be stationary during the time period GPS data cluster within each ellipse.

Prior to 30 January 2006, when C16 finally drifted free, the ellipses representing stable, long-term clusters of the GPS readings were distributed across a $13 \mathrm{~km}^{2}$ area. Careful examination of the GPS data from B15A and B15J (see Okal, 2005, for details) revealed that movement of C16's GPS from one ellipse to another was associated with abrupt changes in the trajectory of one of the two free icebergs, B15A or B15J, confirming collision as the cause of the 'ellipse migration'. C16's movement is thus interpreted to be simply the repositioning of the grounded iceberg on the seabed shoal in 


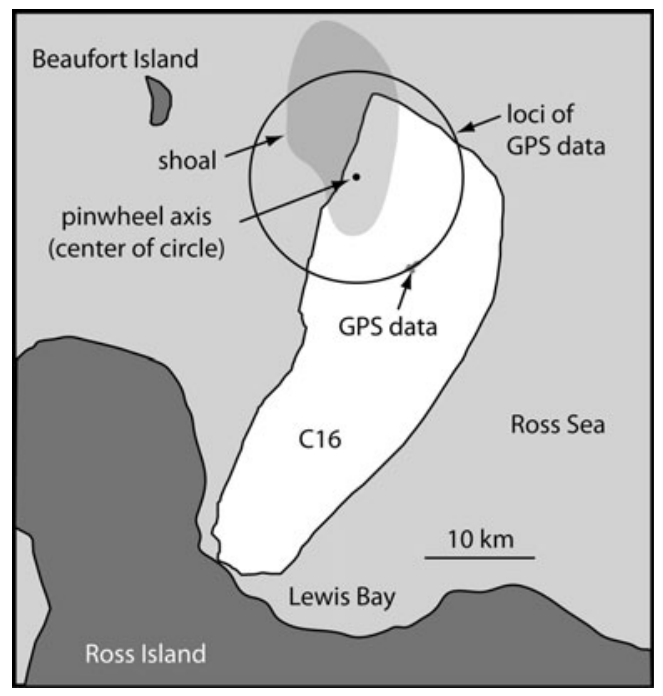

Fig. 6. The arc of GPS positions seen in Figure 5 is part of a circle centered on a point above a shoal east of Beaufort Island. C16's main point of grounding was at the center of this circle (Okal, 2005). This location is verified by the photograph of grounding damage shown in Figure 7. Pinwheel movement of $\mathrm{C} 16$ about the center of this circle occurred several times during the 2001-06 period of C16's grounding in response to collisions with B15A or B15J, which jarred the southern end of C16 loose from an additional area of grounding along the shoreline of Ross Island. The location of the shoal (shaded region) is inferred from bathymetry compiled by Davey (2004).

response to the force associated with iceberg collision. The sequence of movements of $\mathrm{C} 16$ in response to collisions with its partner icebergs is shown in Figure 5.

The other major feature of C16's GPS data is embodied in four major arc-like transient excursions that extend northeastward from ellipse clusters 1 and 2 shown in Figure 5 (see Okal, 2005). These arcs occur during travel between one ellipse and the next, and are completed in less than 24 hours, consistent with tidal forcing as the main cause of the motion. A possible explanation for these arcs is that C16 was usually grounded in two places, one near the northwest corner and the other near the south end. When C16 is struck by B15A, the south end becomes loose and C16 is able to pinwheel on the single grounding point on the northwest corner for a period of roughly one tidal cycle. After an arc is created by the motion, the south end of $\mathrm{C} 16$ runs aground again and the motion stops. To test this hypothesis, each of the arcs was fitted to a circle using a least-squares approach, in which the unknown center and radius of the circle were determined by minimizing the distance from the data points to the circle's perimeter (see Okal, 2005, for details).

The most striking and robust example of the arcs gives a grounding point located in the northwest corner of the iceberg, shown in Figure 6. This location corresponds with the position of a shoal located southeast of Beaufort Island (Davey, 2004). An aerial photograph of the suspected area of grounding was obtained by Y. Arthus-Bertrand. This photograph, shown in Figure 7, depicts the edge of C16 at the point of grounding shown in Figure 6 as viewed from the west looking toward the east. The pieces of C16 in the foreground of the aerial photograph are the result of the iceberg being pushed over the grounding point. This pushing causes the iceberg to arch at the grounding point,

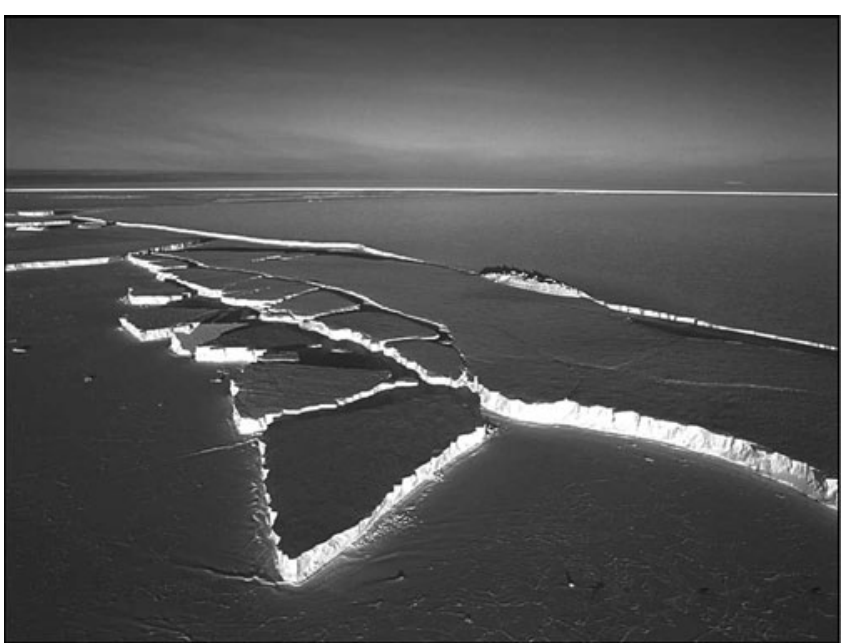

Fig. 7. Aerial photograph of C16 looking northeast from a position just west of the pinwheel axis shown in Figure 6. B15A looms on the horizon behind $\mathrm{C} 16$. In addition to serving as an axis for pinwheel motions, the grounding site serves as a place where the iceberg is flexed as it is pushed across the shoal in response to collisions with B15A and B15J. As the iceberg flexes, small pieces break off due to arching effects. The large mound of surface debris seen along the edge of C16 is a push mound, similar to those shown in Figure 2. (Photograph courtesy of Y. Arthus-Bertrand, artist in residence at McMurdo station during the 2004/05 austral summer season.)

and offers a mechanical impetus to break the iceberg on the distal side (in the foreground of the photograph) of the grounding point.

\section{Kinematics of moving icebergs B15A and B15J}

Above, we described the kinematics of a grounded iceberg during a long episode of being struck by other icebergs. Next, we turn our attention to the movements of icebergs which struck this grounded iceberg as well as both land and ice-shelf coastal features. A 9 month subset of the trajectory of one of the two AWS/GPS stations on B15A prior to the calving of $\mathrm{C} 19$ is displayed in Figure 8. Three important characteristics of the movement are demonstrated by this trajectory. The first is the nearly constant motion of the iceberg. The second is the dominance of tidal motion that causes the trajectory to be composed of small loops and other nearly closed, repeated patterns. The velocity magnitude of the iceberg (Fig. 9) shows that the diurnal tide dominates daily motion, and variability at longer timescales is dominated by the spring-to-neap tidal cycle. Comparison of the iceberg's motion with tidal currents and sea-surface variation in the area (Robertson and others, 1998; see also http://esr.org) shows that the iceberg's motion is consistent with being driven by the tides. The constant motion of B15A during the time period prior to its split into B15A and B15] (25 January 2001 to 8 October 2003) is difficult to glean from a plot of the trajectory of the AWS/GPS station, because the trajectory forms a mass of overlapping lines that are difficult to visually comprehend. To overcome this difficulty, a histogram of the iceberg's cumulative daily movement (distance traveled in a day along a curvilinear path, regardless of the distance between start and end points of the path) is shown in Figure 10.

The third, and most important, characteristic displayed by B15A's trajectory is the presence of boundaries along which 


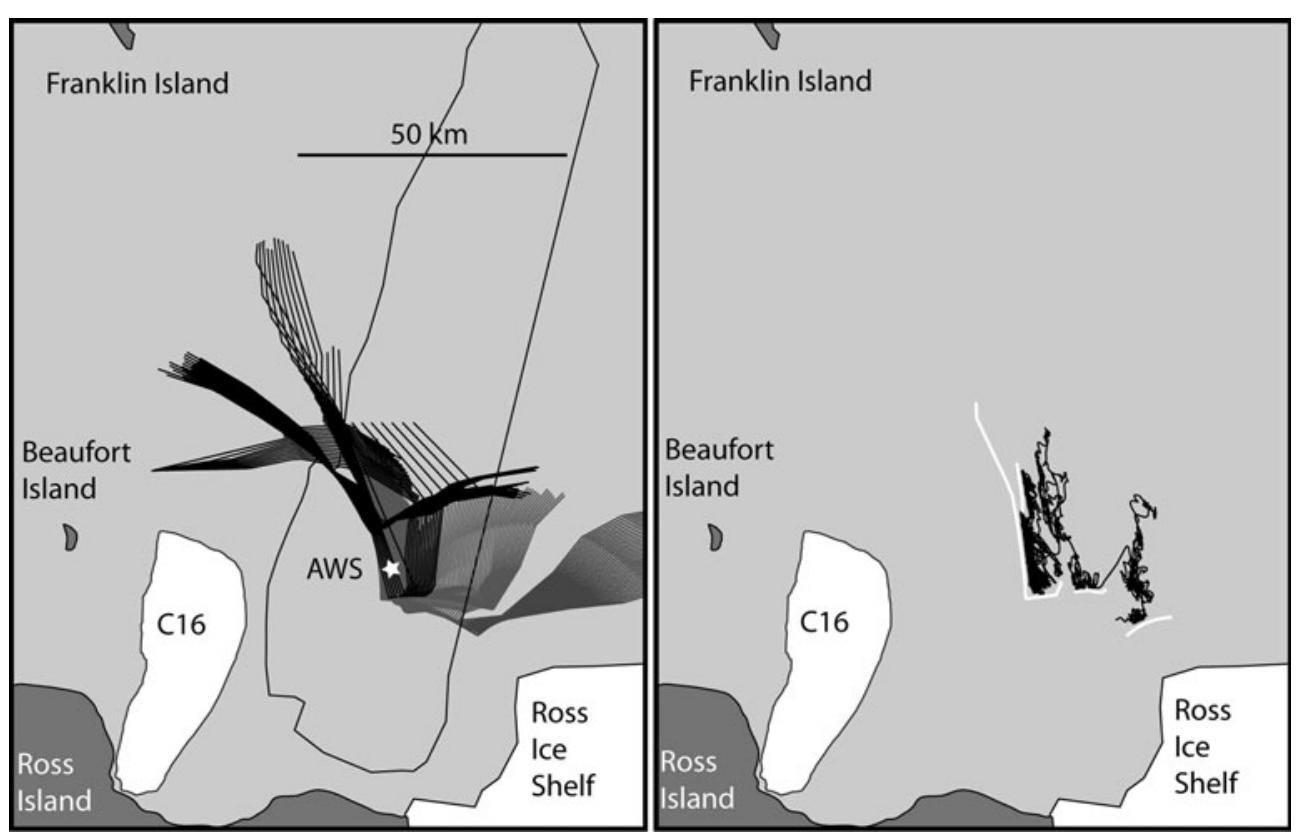

Fig. 8. Left panel: family of lines representing boundaries to possible motion of the GPS station on B15A during August 2001 to May 2002 , immediately prior to the calving of $\mathrm{C} 19$ (north up). These lines are parameterized by the angular orientation of the iceberg as it is translated arbitrarily within the confined space between C16, Ross Island and the Ross Ice Shelf. The outline of B15A represents a snapshot of its location at an arbitrary time during the time period over which the trajectory is displayed. Right panel: dark line is the observed trajectory of the GPS station on B15A. White lines are select boundaries from the left panel which display constraints to the trajectory of the iceberg. Accumulation of the trajectory along the white lines indicates that B15A's motions were strongly constrained by collisions with C16, Ross Island and the Ross Ice Shelf. Even though the white lines of constraint in the right panel do not form a closed boundary, the long-term effect of their limitations to B15A's motion was to make it difficult for the iceberg to drift north, away from Ross Island.

trajectories accumulate (denoted by white lines in the right panel of Fig. 8). The origin of these boundaries stems from the simple fact that the iceberg possesses a relatively rigid shape which must key within a region bounded by rigidly shaped objects (other icebergs, coastlines and ice fronts).

To demonstrate this keying effect, a series of geometric manipulations were performed with the map of the region using the rigid shape of B15A determined from satellite imagery. The results of the manipulations, namely the computation of families of boundaries that depend on iceberg orientation and initial position, are shown in the left panel of Figure 8. The algorithm used to compute the families of boundaries was simple: for a number of arbitrarily chosen initial iceberg positions, the iceberg's outline was translated on the map of the region until the outline struck a boundary. The locations of the GPS on the iceberg at the points where the translated outline struck a boundary were recorded, and the curves created by such points represent edges of the keyholes into which the iceberg's shape is permitted to turn.

As shown in Figure 8, the boundaries that constrain B15A's trajectory form distinctive patterns along which trajectories must accumulate. The fact that these boundaries shift with changing iceberg orientation explains the complexity seen in the subsample of B15A's trajectory shown in the righthand panel of Figure 8. The full record of B15A's trajectory (not shown) displays many examples of trajectory accumulations along boundaries determined by rigid-body geometry. Some boundaries, such as those highlighted in Figure 8, appear to persist for long periods while others are more ephemeral; this suggests that some orientations of the iceberg were more persistent than others.

\section{FORCES OF ICEBERG COLLISIONS}

An initial step in understanding the effect of collisions on iceberg behavior in the near-coastal environment is the estimation of forces acting on the icebergs necessary to explain their trajectories. In the following analysis, the icebergs are treated as point masses located at the iceberg centers of area, and force vectors (resting in the horizontal plane) derived from the analysis represent the ocean, atmosphere and sea-ice forces that will not be decomposed further. Although it is of interest to prioritize the aspects of an iceberg's surroundings according to the forces they impart on the iceberg, such a prioritization is beyond the scope of the present data, where little is known about wind (aside from at the AWS locations situated on the icebergs), ocean current or sea-ice stress across the full spans of the various icebergs studied.

It is appropriate to list the problems arising from rigidbody constitutive properties and observational uncertainties that hamper the force analysis that follows. Rigid-body dynamics is organized into a free-motion form and a static form. The free-motion form is applicable when the body can accelerate freely in response to forces, and is thus not in contact with other rigid features. In circumstances where the iceberg under analysis is freely moving across the ocean surface (we presume a hydrostatic balance accounts for the vertical degree of freedom at all times), the acceleration of the iceberg's center of mass as measured by our instrumentation is directly related to the sum of surface and body forces acting on the iceberg by Newton's law.

The second form of rigid-body dynamics is the static form, where the body displays acceleration and motion that is 


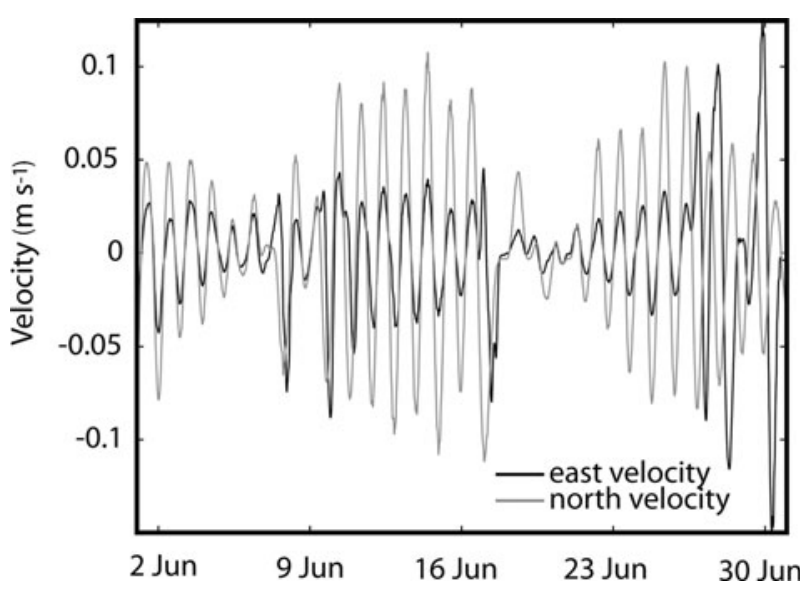

Fig. 9. Velocity components of B15A during June 2002, several weeks after the 11 May 2002 calving of C19. The strong diurnal variability is associated with the fundamental role of the ocean tide in exciting iceberg motion (Padman and others, 2003). Spring-toneap tidal cycles are visible in the modulation of the amplitude envelope of the diurnal signal. The limited time period over which velocity is shown here provides a detailed view of how the iceberg would move near Ross Island in the absence of collisions. Over the much greater period of time that B15A was resident in the Ross Island area, its velocity was a combination of free, tidally driven motion, such as shown here, and motion constrained by collision, where velocity in one or two directions was stopped for limited periods of time.

limited in one or more spatial dimensions by contact with other rigid bodies. In this case, the force balance is determined by statics, and includes forces of constraint generated at points of rigid-body contact. When an iceberg is in contact with other rigid elements of the environment (e.g. seabed, coast or other icebergs) the net force is invisible to analytical techniques that only use iceberg movement as the means of evaluating forces. Our data, consisting of only point-wise observations of iceberg motion, are insufficient to conduct such static analysis; thus, at times when the icebergs are in collision the forces remain unknown. We shall assume, however, that the forces derived from periods of time immediately prior to collisions, when the iceberg was in free motion, are roughly the same magnitude as the forces resulting from a static analysis.

Observational uncertainty and measurement error are also a concern in the estimation of forces acting on icebergs. The greatest source of observational uncertainty is in the iceberg thickness necessary to evaluate iceberg mass. Radio-echo sounding profiles of B15A reported by Peters and others (2007; also J. Holt and D. Blankenship, personal communication, 2005; see also Bentley and others, 1979) suggest a range of thickness averaging $\sim 250 \mathrm{~m}$. At the central AWS site on $\mathrm{C} 16$, the thickness was observed to be $144 \pm 14 \mathrm{~m}$ using a hand-held spot radar. At several points along the edge, the thickness was as low as $26 \pm 3 \mathrm{~m}$. The thickness of the tip of the Drygalski Ice Tongue, from which iceberg C25 calved, was estimated to be $300 \mathrm{~m}$ based on reports of a recent remote-sensing survey (see Frezzotti and Mabin, 1994; Parmiggiani and Fragiacomo, 2005). Using 250, 100 and $300 \mathrm{~m}$ for the average thicknesses of icebergs B15A, C16 and $\mathrm{C} 25$, their areas measured from satellite imagery, and a density of $900 \mathrm{~kg} \mathrm{~m}^{-3}$, the masses of the icebergs were estimated to be $2.7 \times 10^{15}, 6.5 \times 10^{14}$ and $9.7 \times 10^{13} \mathrm{~kg}$,

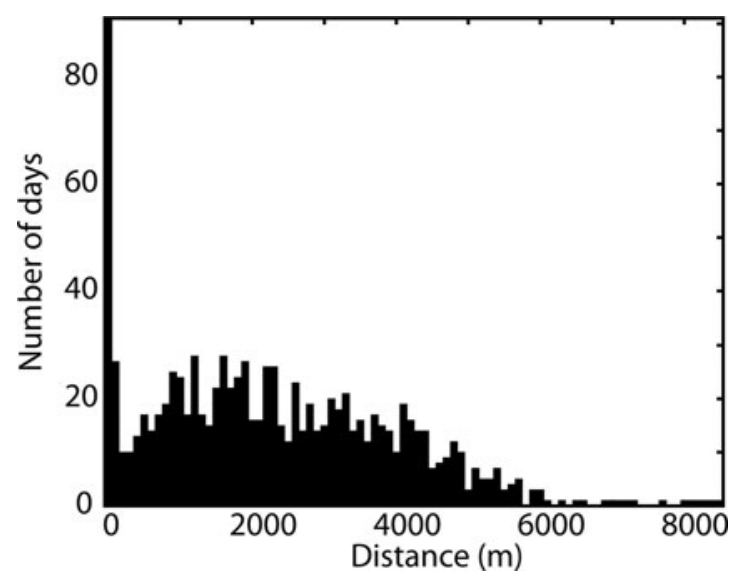

Fig. 10. Histogram of daily movement (cumulative distance traveled in 24 hours along curvilinear trajectory) for B15A prior to splitting into B15A and B15J (25 January 2001 to 8 October 2003). Bin width is $100 \mathrm{~m}$. For 90 of the 985 daily samples, B15A's cumulative movement in a day was $<100 \mathrm{~m}$. This spike in the histogram reflects the effects of collisions and collisional contact which wedged B15A into a position between C16, Ross Island and the Ross Ice Shelf. The purpose of the histogram is to convey a sense of the magnitude of daily movement that cannot be appreciated from the maps of iceberg trajectory (e.g. Fig. 8), where the line denoting the trajectory is tightly folded and confined within a narrow region.

respectively. Uncertainty in these values is difficult to estimate conclusively, but we believe that the mass values given above are within $25 \%$ of the actual values.

The principal source of measurement error, treated as distinct from observational uncertainty, is noise associated with the GPS data. Measurement errors translate into noise when the position of the iceberg's center of mass is differentiated twice with respect to time to give acceleration. To cope with the effects of this error, we adopt the leastsquares estimation technique described below. The net effect of this technique is to allow the computation of a smooth iceberg trajectory associated with forces that change slowly in time (i.e. not on a minute-by-minute basis, but rather over hours) and which fits the observed trajectory within misfit tolerances derived from instrument accuracy (e.g. for GPS position $\sim 10 \mathrm{~m}$ ).

\section{Force equation}

We treat the icebergs as point masses with zero moment of inertia. The Coriolis force and one part of a linear oceanfriction force are treated explicitly, since they are simple functions of the observed iceberg trajectory. For ocean friction, a linear drag law replaces the more common quadratic law to linearize the mathematical system. In this case, relative motion between the ice and the sea water at the iceberg base, which is the origin of ocean frictional force, is decomposed into two parts. The part that depends on the iceberg's motion relative to the solid Earth (e.g. as would apply if ocean currents were at rest) is treated explicitly. The part that depends on non-stationary ocean currents relative to the solid Earth is left unresolved, and is lumped together with all other unresolved forces acting on the iceberg to be determined from the analysis.

The remaining surface and body forces (i.e. not counting Coriolis force and one part of the ocean friction described above, which are treated explicitly) are lumped together and 
denoted by the vector $\mathbf{F}(t)$. The equation for force balance is,

$$
M \frac{\mathrm{d}^{2} \mathbf{X}}{\mathrm{d} t^{2}}+M f \mathbf{n}_{z} \frac{\mathrm{d} \mathbf{X}}{\mathrm{d} t}+C_{\mathrm{d}} A \frac{\mathrm{d} \mathbf{X}}{\mathrm{d} t}=\mathbf{F}(t),
$$

where $\mathbf{X}=(x, y)$ is the vector position of the iceberg's center of mass (typically relative to an origin associated with an appropriately scaled map projection: a Lambert azimuthal equal area map projection centered on the South Pole; thus, $x$ and $y$ denote Cartesian coordinates on this map), $\mathrm{d} \mathbf{X} / \mathrm{d} t=$ $\mathbf{U}=u \mathbf{n}_{x}+\mathbf{n}_{y}$ is the horizontal velocity vector with horizontal components $u$ and $v, \mathbf{n}_{x}$ and $\mathbf{n}_{y}$ are unit vectors in the $x$ and $y$ directions, $M$ is the mass of the iceberg, $f=2 \Omega \sin \phi$ is the Coriolis parameter, $\Omega=2 \pi / 86400 \mathrm{~s}^{-1}$ is the angular velocity of Earth rotation, $\phi$ is latitude, $C_{d}=10^{-5} \mathrm{Ns}$ is a linear drag coefficient representing ocean resistance to iceberg motion, $A$ is the iceberg area (in the horizontal map plane, evaluated from satellite imagery), $\mathbf{F}(t)$ is the force vector representing the desired objective of the data analysis and $t$ is time. Variables in boldface are vectors.

The variable $\mathbf{F}(t)$ represents the residual of all surface and body forces acting on the iceberg that are not either the Coriolis force or the linear oceanic drag that are explicitly treated on the lefthand side of Equation (1). This residual force arises from: (1) wind stress on the upper, horizontal surface and sides of the iceberg; (2) frictional stress on the bottom, horizontal surface and sides of the iceberg that arises from ocean currents not accounted for by the lineardrag term on the lefthand side of Equation (1); (3) the effect of the ocean surface's dynamic topography and sea-surface tilt associated with tides; (4) the effect of sea ice acting at around the perimeter of the iceberg, where the relative motion between sea ice and the iceberg is convergent; and (5) the effect of differential atmospheric pressure acting on the freeboard of the iceberg. The lefthand side of Equation (1) represents quantities that are observed.

When the iceberg is freely adrift, the net force, $\mathbf{F}(t)$, deduced from evaluating the lefthand side of Equation (1) represents a meaningful sum of surface and body forces acting on the iceberg (in addition to the Coriolis force and a linear drag, which are bundled on the lefthand side of Equation (1)). When the iceberg is static, the first and second time derivatives of $\mathbf{X}$ are zero, giving $\mathbf{F}=0$. This means that forces arising from sea-surface tilt and fluid interactions around the iceberg's surfaces are exactly balanced by forces of constraint associated with rigid-body contact. Normally, these forces of constraint will produce elastic and viscous deformation within the iceberg that are diagnostic of the state of internal stress. These deformations are not observed, however, so the forces arising from constraint cannot be evaluated explicitly. Given the long time period over which $\mathbf{X}$ is observed, and the consistency of the derived $\mathbf{F}$ during times when free drift applies, we assume that forces of constraint associated with rigid-body contact are roughly the same in pattern and magnitude as the derived $\mathbf{F}$ during free drift.

\section{Least-squares methodology}

To estimate $\mathbf{F}(t)$ from the observed iceberg trajectory, we adopt a least-squares method described by Wunsch (1988). A least-squares performance index, $J$, is defined in terms of a misfit between a model-derived trajectory $\mathbf{X}(t)$ and the trajectory observed by the iceberg instrumentation, denoted by a subscript ' 0 ': $\mathbf{X}_{0}(t)$. A smoothness constraint on $|\mathrm{d} \mathbf{F} / \mathrm{d} t|$ is added to $J$ as a measure to control impulsive, sudden forces arising only from measurement error and noisy data.
The minimization of $J$ is constrained by the requirement that Equation (1) be satisfied subject to (for convenience) initial and terminal conditions (i.e. at $t=t_{\mathrm{s}}$ and $t=t_{\mathrm{e}}$, where subscripts ' $\mathrm{s}$ ' and ' $\mathrm{e}$ ' denote start and end time, respectively) specifying $\mathbf{X}=\mathbf{X}_{0}$. Constraints are enforced using a vectorvalued Lagrange undetermined multiplier denoted by $\mu(t)$ (in Wunsch, 1988, this variable is called the adjoint trajectory). The expression for $J$ is:

$$
\begin{aligned}
J= & \int_{t_{\mathrm{s}}}^{t_{\mathrm{e}}}\left\{\left[x(t)-x_{0}(t)\right]^{2}+\left[y(t)-y_{0}(t)\right]^{2}\right. \\
& \left.+\varepsilon\left[\left(\frac{\mathrm{d}^{2} x(t)}{\mathrm{d} t^{2}}\right)^{2}+\left(\frac{\mathrm{d}^{2} y(t)}{\mathrm{d} t^{2}}\right)^{2}\right]\right\} \mathrm{d} t \\
& +\int_{t_{\mathrm{s}}}^{t_{\mathrm{e}}} \mu\left[M \frac{\mathrm{d}^{2} \mathbf{X}}{\mathrm{d} t^{2}}+M \mathbf{n}_{z} \frac{\mathrm{d} \mathbf{X}}{\mathrm{d} t}+C_{\mathrm{d}} A \frac{\mathrm{d} \mathbf{X}}{\mathrm{d} t}-\mathbf{F}(t)\right] \mathrm{d} t
\end{aligned}
$$

where $\varepsilon$ is an empirically derived parameter determining the trade-off between fitting the observed trajectory and deriving a smoothly varying forcing schedule. Although not explicitly stated in the expression for J, two boundary conditions are required by the second-order differential equation appearing in the second integral on the righthand side. For simplicity, we invoke initial and terminal constraints, i.e. $\mathbf{X}\left(t_{\mathrm{s}}\right)=\mathbf{X}_{0}\left(t_{\mathrm{s}}\right)$ and $\mathbf{X}\left(t_{\mathrm{e}}\right)=\mathbf{X}_{0}\left(t_{\mathrm{e}}\right)$.

Without loss of generality, we require initial and terminal conditions on $\mu: \mu\left(t_{\mathrm{s}}\right)=0$ and $\mu\left(t_{\mathrm{e}}\right)=0$. After integration by parts to simplify variations with respect to differentiated variables, the Euler-Lagrange equations to be satisfied to obtain $\partial J=0$ are:

$$
\begin{aligned}
& M \frac{\mathrm{d}^{2} \mathbf{X}}{\mathrm{d} t^{2}}+M f \mathbf{n}_{z} \frac{\mathrm{d} \mathbf{X}}{\mathrm{d} t}+C_{\mathrm{d}} A \frac{\mathrm{d} \mathbf{X}}{\mathrm{d} t}-\mathbf{F}(t)=0 \\
& M \frac{\mathrm{d}^{2} \mu}{\mathrm{d} t^{2}}+M f \mathbf{n}_{z} \frac{\mathrm{d} \mu}{\mathrm{d} t}+C_{\mathrm{d}} A \mu=\frac{1}{2}\left[\mathbf{X}_{0}(t)-\mathbf{X}(t)\right]-\frac{\varepsilon}{2}\left[\frac{\mathrm{d}^{4} \mathbf{X}(t)}{\mathrm{d} t^{4}}\right](4) \\
& \mu=0 .
\end{aligned}
$$

Observe that the conditioning term appearing in $J$ has been converted into a fourth-order time derivative by integration by parts.

Discretization of the Euler-Lagrange equations (3-5), is straightforward using second-order (leapfrog) finite-difference forms for single time derivatives and a first-order form of the second-order (Laplacian) time derivative. The resulting algebraic equations for discretized values of $\mathbf{X}, \mathbf{F}$ and $\mu$ associated with discrete time-steps $(\Delta t=20 \mathrm{~min})$ were solved using LU decomposition and back substitution for the desired trajectory, forces and undetermined multiplier variables. Treatment of matrix sparseness was essential, and was easily accomplished using sparse-matrix routines provided by the Matlab ${ }^{\mathrm{TM}}$ software package. The smoothing parameter, $\varepsilon$, was specified to be $10^{-17}$ on the basis of the resulting fit between observed and computed trajectories. The mean misfit between the two trajectories was typically $<40 \mathrm{~m}$, a value commensurate with the accuracy of the nongeodetic GPS instrumentation used to provide the data. The key effect of the smoothing parameter was to eliminate sudden, impulsive changes of the derived force on timescales clearly related to the time-step to time-step sampling interval of the measurement instruments. 


\section{DISCUSSION OF DERIVED FORCES}

We present the force-balance analysis of the iceberg trajectory data during three episodes of particular interest. We note at the outset that uncertainty in the mass and area of each iceberg probably introduces an uncertainty in the magnitude of $\mathbf{F}$ estimated to be $\sim 25 \%$. (This estimate represents a subjective opinion, and is not derived from formal error analysis.) We expect the accuracy of relative changes in the magnitude and direction of $\mathbf{F}(t)$ encountered over the time period of observation to be approximately $5 \%$ and $5^{\circ}$, respectively, as relative changes are less influenced by the uncertainty of mass and area. The first episode of interest is from January to June 2002, when C16 was bumped 19 times by B15A with sufficient energy to force C16 to slide over its seabed pinning points. Iceberg C19 was also calved during this time period (11 May 2002). The second episode of interest is from 27 March to 5 April 2006, when C16 was adrift and struck the Drygalski Ice Tongue on 29 March 2006, causing the tip of the ice tongue to break off and become C25. Of particular note for this collision event is that GPS receivers were deployed on both C16 and Drygalski/ C25 at the time, allowing $\mathbf{F}$ to be separately evaluated for both icebergs. The third episode of interest is from 20 October to 5 November 2005, during the time B15A broke up near Cape Adare as it exited the Ross Sea on an eastward drift trajectory. Evidence suggests (Martin and others, 2007; see also MacAyeal and others, 2006) that B15A was rubbing on shoals off Cape Adare at the time of break-up.

\section{Episode 1: B15A collides with C16, Ross Island and the Ross Ice Shelf}

The observed trajectory of the center of mass of B15A, as deduced from the GPS data on the iceberg during the January 2001 to June 2002 time period, is displayed in Figure 11. Except for some excursion to the northeast, much of this trajectory is focused along the boundaries of constraint imposed by the collisional geometry of B15A and the surrounding objects (C16, Ross Island and the Ross Ice Shelf).

In Figure 12, the magnitudes of the velocity and force, $|\mathbf{U}(t)|$ and $|\mathbf{F}(t)|$, respectively, derived from the least-squares analysis described in the previous section are displayed for the time period of interest. Along the horizontal time axis of the lower panel in Figure 12, reference is made to the GPS position clusters associated with C16's movements displayed in Figures 4 and 5. This reference highlights the times at which forces of collision induced by B15A's striking C16 were sufficient to push $\mathrm{C} 16$ by small increments over the shoal on which it was grounded.

The velocity of B15A during episode 1 ranges from 0 to a maximum just over $0.6 \mathrm{~m} \mathrm{~s}^{-1}$ (slightly over $1 \mathrm{knot}$ ). The force magnitude ranges from 0 to just under $20 \times 10^{10} \mathrm{~N}$. When we refer to force magnitude here and elsewhere, we are referring to $|\mathbf{F}(t)|$, not $\left|\mathrm{d}^{2} \mathbf{X}(t) / \mathrm{d} t^{2}\right|$. Times when $\mathrm{C} 16$ was moved across the grounding points (see Figs 4 and 5 , and Okal, 2005) are highlighted in Figures 11 and 12 by bold lines. Three aspects of the velocity and force magnitudes shown in Figure 12 are noteworthy. First, the force magnitude appears to mimic the velocity magnitude as a sequence of diurnally repeated pulses that are modulated by a spring-to-neap tidal cycle. This modulation is not perfect, as the process of collision interrupts the regularity of tidal movements; however, this modulation suggests that the main contributor to the force balance defining $|\mathbf{F}(t)|$ is tidal

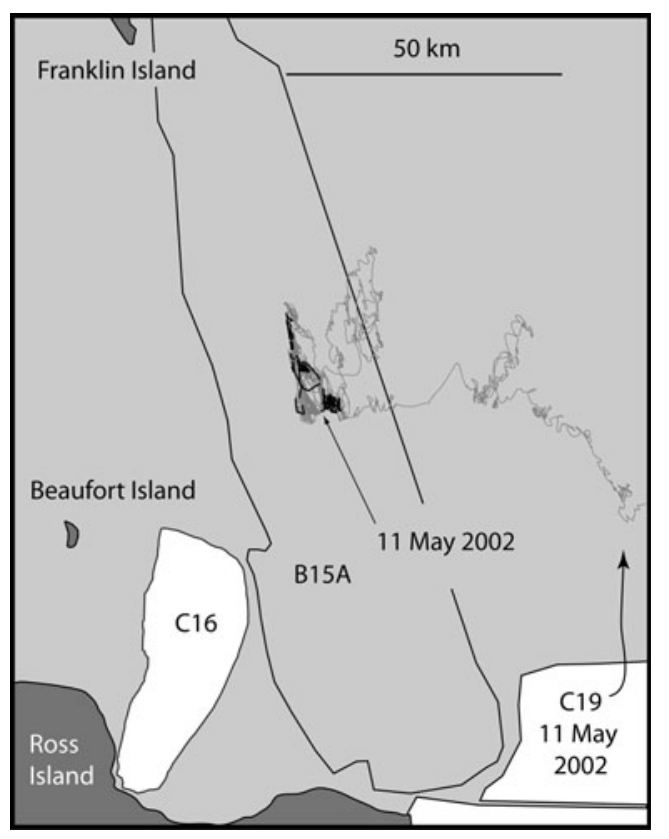

Fig. 11. Trajectory of $B 15 A^{\prime}$ s center of area (computed from observations made at two GPS sites located elsewhere on the iceberg) from January 2001 to June 2002 (light gray line). The trajectory segments associated with dates when C16 was pushed across its grounding point by B15A (see Fig. 4 and Okal, 2005) are highlighted as bold, black lines. The movement of B15A at the time C19 was calved on 11 May 2002 suggests that B15A and C16 acted like a lever and fulcrum helping to spring C19 free of the Ross Ice Shelf. The bold, black portion of the trajectory immediately following the calving indicates that B15A was in contact with C16 at the time C19 was prized free of the Ross Ice Shelf. The movement of B15A during 11 May 2002 involved translation of the center of mass to the east (into the region covered by the mass of bold trajectory lines immediately to the right of the point indicated by the arrow) and counterclockwise rotation that maintained B15A and C16 in contact and allowed the southern end of B15A to rotate toward contact with the part of the Ross Ice Shelf which became iceberg C19. Contact between the three icebergs is also supported by satellite imagery immediately after the calving (see http:// ice.ssec.wisc.edu/ice_images/icebergs/ross/2002/ROS02131.GIF). The outline of $\mathrm{B} 15 \mathrm{~A}$ represents its approximate position just prior to the calving of C19.

in origin. Analysis of how ocean tide and large icebergs interact in shallow, continental-shelf seas is motivated by the present results, but shall be addressed in future research, because it is unclear whether tidal currents and perturbations to the sea surface can be estimated from tidal models (e.g. Padman and others, 2003) that do not account for the presence of the iceberg.

The second noteworthy aspect of the velocity and force magnitude is that periods of high magnitudes do not appear to be a necessary condition for pushing C16 across its grounding zone. Several of C16's movements noted in Figures 4 and 5 (see also Okal, 2005) occur during relative minima of velocity and force magnitude derived from B15A's trajectory. Third is the fact that C19 appears to have calved following a long period when B15A was immobile, i.e. when our analysis records neither velocity nor force. This suggests that the invisible (to our instruments) forces of constraint associated with static arrangements of rigid bodies in contact were at play when C19 calved. As shown in Figure 11, the first motion immediately following the calving 


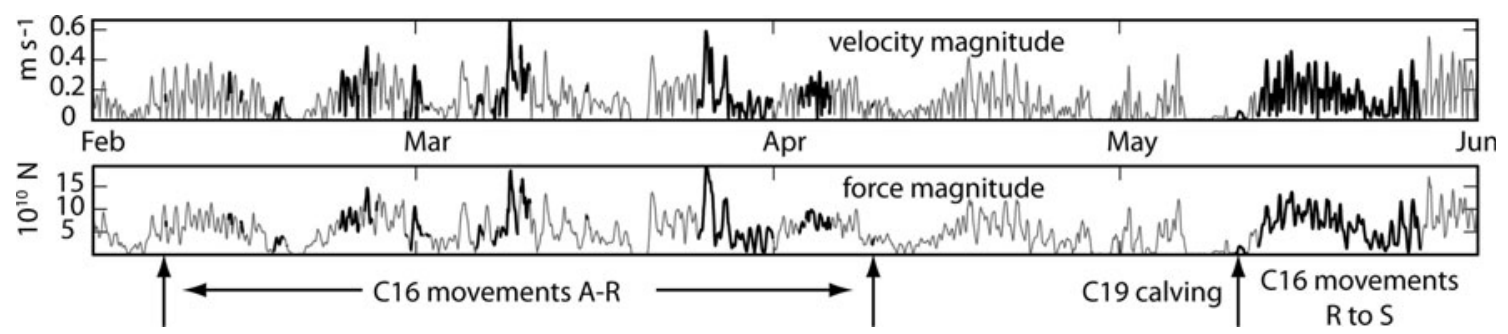

Fig. 12. Velocity (upper panel) and force (lower panel) magnitudes derived for B15A during the period of 2002 when it collided with C16, and when it contributed to the calving of C19. Along the horizontal time axis of the lower panel, reference is made to the GPS position clusters associated with C16's movements displayed in Figures 4 and 5. Segments of the graphs highlighted in bold and black correspond to periods identified by Okal (2005) when C16 was pushed over its grounding point. Comparison of the upper and lower panels suggests that the spring-to-neap tidal cycle apparent in the iceberg velocity magnitude is also apparent in the force. This similarity suggests that the force is generally associated with tidal effects, i.e. the slope of the sea surface across which the iceberg slides in response to gravitational acceleration. The force magnitude scale shown here for the day immediately after the calving of C19, taken to be $5 \times 10^{10} \mathrm{~N}$, is used to estimate a rough stress magnitude scale to be applied over the area of the vertical face of a $40 \mathrm{~km}$ rift necessary to rupture the remainder of C19's detachment rift on the day of calving (Joughin and MacAyeal, 2005). This rough magnitude is $6 \times 10^{3} \mathrm{~Pa}$, and can be used as a rule-ofthumb when considering stresses adequate to induce iceberg calving from the Ross Ice Shelf. A similar analysis of force magnitudes applicable when C16 was pushed over its seabed pinning point yields a strength scale for the iceberg's basal contact with the seabed that is $\sim 3 \times 10^{3} \mathrm{~Pa}$.

of C19 was for B15A to move east. This initial movement suggests that B15A had a role in prizing C19 loose from the Ross Ice Shelf.

\section{Episode 2: C16 collides with the Drygalski Ice Tongue, causing C25 to calve}

The observed trajectory of the center of mass of C16, as deduced from GPS and magnetic compass data, during the

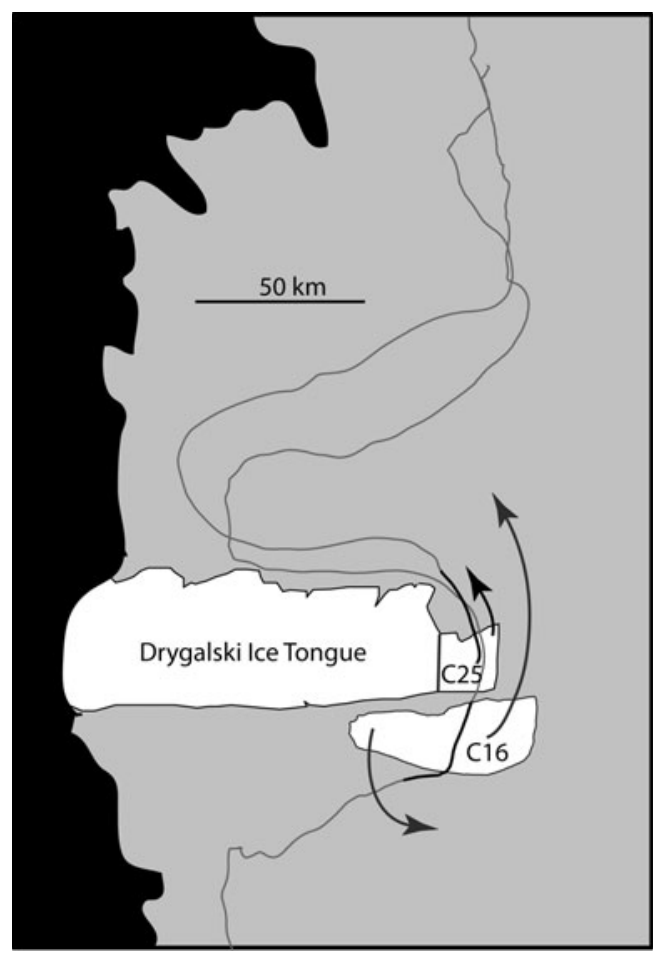

Fig. 13. Trajectories of $\mathrm{C} 16$ and $\mathrm{C} 25$ during an 11 day period surrounding the calving of $\mathrm{C} 25$, which was stimulated by the collision between C16 and the Drygalski Ice Tongue. The trajectories during the day of calving (29 March 2006) are highlighted in bold. Immediately following the calving of C25, C16 rotated $90^{\circ}$, as indicated by the arrows. Both C16 and C25 transited through Terra Nova Bay north of the Drygalski Ice Tongue in a matter of days.
11 day period in March and April 2006 when C25 calved from the Drygalski Ice Tongue is displayed in Figure 13. Velocity magnitudes and components for C16 and C25 derived from the least-squares method are displayed in Figure 14, and the force magnitudes for both icebergs are displayed in Figure 15. As with B15A immediately prior to the calving of C19 (May 2002), the calving of C25 on 29 March 2006 corresponds with a period when the motion of the striking iceberg (C16) was constrained and static in at least one dimension. As seen in Figure 14, C16's north-south velocity is zero for a number of hours prior to the calving of C25. The east-west velocity of $\mathrm{C} 16$ was also reducing during this time. The constraint in C16's motion immediately prior to calving suggests that the forces that normally would have accelerated C16, arising from ocean and atmospheric interaction, were transferred to the Drygalski Ice Tongue through iceberg/ice-tongue contact. These transferred forces would be the source of stress that ultimately broke the ice tongue, yielding iceberg C25 from its tip.

Once C25 calved, C16 became mobile again and C25 quickly accelerated to conform to the same general movement as C16, i.e. moving around the tip of the remaining part of the Drygalski Ice Tongue. Forces associated with the collision, as deduced by the least-squares method and shown in Figure 15, were not remarkable. C16's movements during the collision suggest a steady force magnitude of $\sim 4 \times 10^{10} \mathrm{~N}$. The force magnitude acting on C25 slowly ramped up from 0 to a maximum of $\sim 2.5 \times 10^{10} \mathrm{~N}$ several hours after being freed from the ice tongue. The forcing of C25 appears to be more noisy than that of C16, and this may reflect the fact that $\mathrm{C} 25$ was scraping past the ice tongue, while $\mathrm{C} 16$ was separated from the ice tongue by virtue of the intervening presence of C25. C16 is also less thick than C25 (estimated to be $\sim 300 \mathrm{~m}$; Frezzotti and Mabin, 1994; Parmiggiani and Fragiacomo, 2005), so edge-on-edge scraping against the Drygalski Ice Tongue would be less effective in restraining C16's motion than it would be in restraining that of $\mathrm{C} 25$.

\section{Episode 3: B15A breaks up near Cape Adare}

The final episode of iceberg behavior highlighted in this study occurred around 27 October 2005, the date B15A 

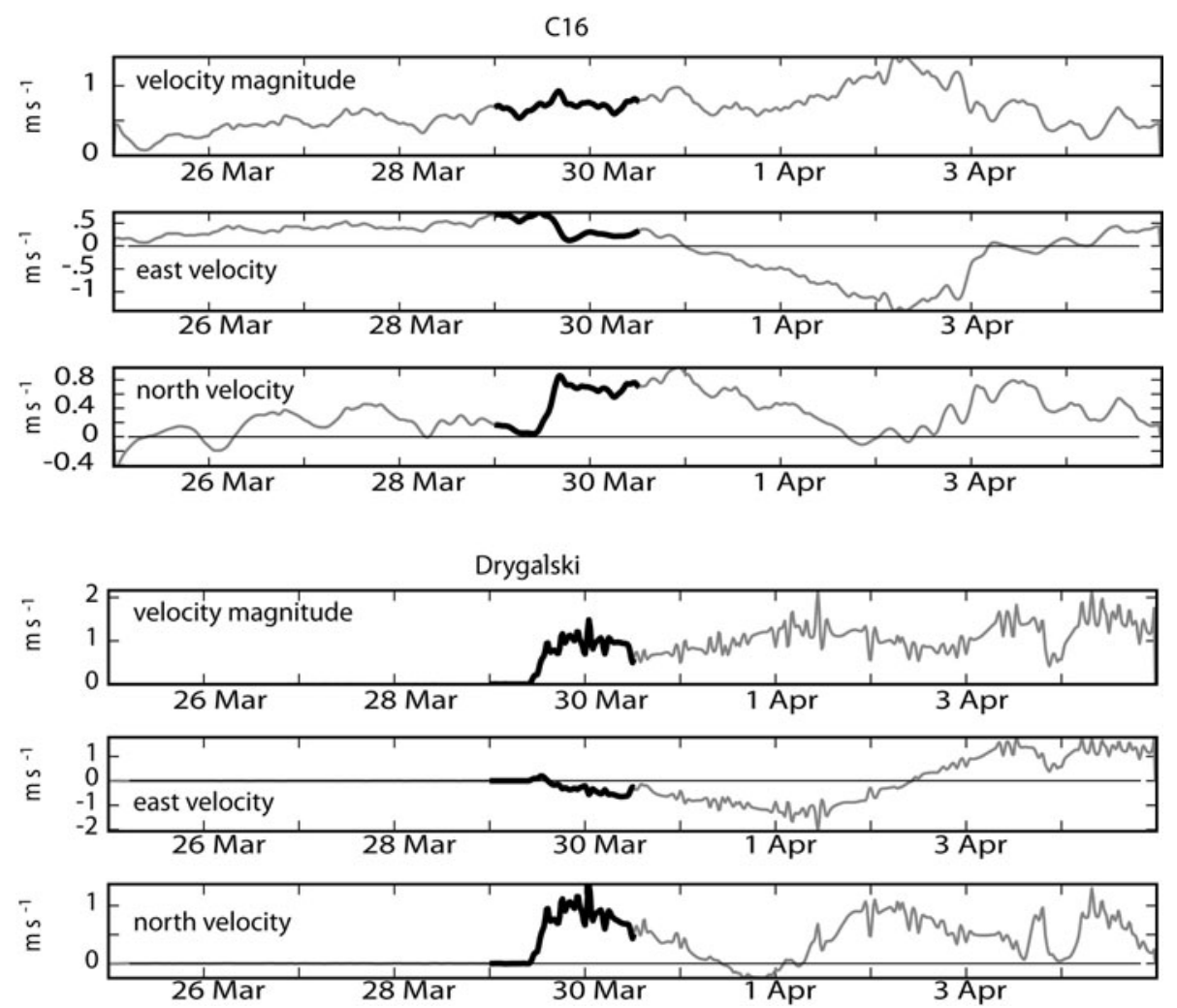

Fig. 14. Velocity of $\mathrm{C} 16$ (upper panels) and $\mathrm{C} 25$ (lower panels) during the 11 day period surrounding the collision between $\mathrm{C} 16$ and the Drygalski Ice Tongue which caused C25 to calve. Velocities on the day of calving are in bold. Immediately prior to calving, C25 is motionless. C25 develops a large northward velocity (parallel to coast and to C16's motion) in several hours after detaching from the Drygalski Ice Tongue. C16's northward velocity is reduced in the day prior to C25's calving, but also increases immediately after the detachment of $\mathrm{C} 25$.

broke into many large pieces off Cape Adare. Some argue that this break-up was a result of the effects of sea swell arriving in the region from a storm in the Gulf of Alaska 6 days earlier (MacAyeal and others, 2006); however, the small amplitude of this swell, as measured by a seismometer located on the western end of the iceberg, suggests there may be another explanation for the break-up, such as the iceberg's interaction with the seabed off Cape Adare (Martin and others, 2007).

The trajectory of the iceberg's center of mass during the period from 20 October to 5 November 2005, is displayed in Figure 16 . The velocity and force time series derived from the least-squares method are displayed in Figures 17 and 18, respectively. Of note in the iceberg's trajectory is the fact that a profound change in the style of motion occurred several days prior to break-up. Prior to about 22 October, B15A was located over the edge of the continental shelf and slope leading to the abyssal ocean beyond the Ross Sea. Topographic vorticity waves are excited by the diurnal tide in this region (MacAyeal, 1984; Padman and others, 2003), and are well displayed by the remarkably large looping motions of the iceberg. These large motions represent the fastest (exceeding $3 \mathrm{~m} \mathrm{~s}^{-1}$, or $\sim 6$ knots) motions recorded for B15A, as well as the largest distances traveled on a daily basis.

Following 22 October, the large looping motions began to subdue, and were replaced with strong linear motions,

C16

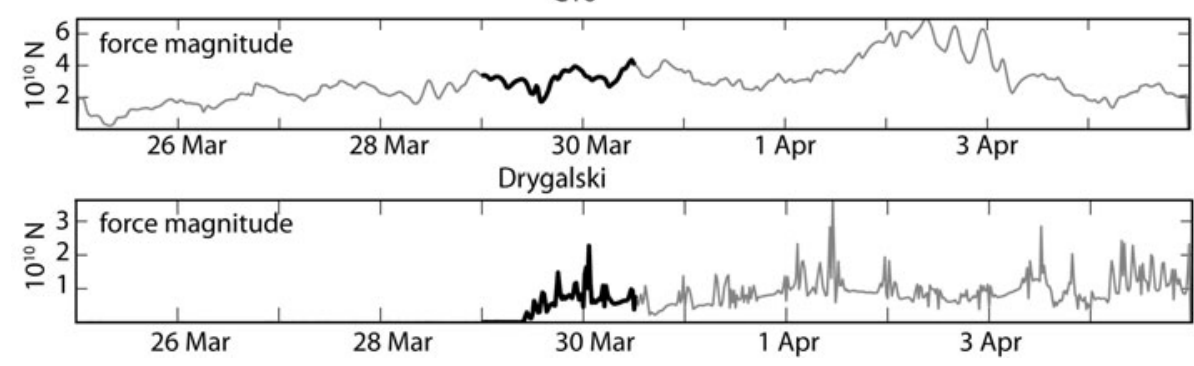

Fig. 15. Force magnitudes computed from the motion of $\mathrm{C} 16$ (upper panel) and $\mathrm{C} 25$ (lower panel) during the 11 day period surrounding the collision of C16 and the Drygalski Ice Tongue that produced C25. The force magnitudes on the day C25 was produced are highlighted in bold. The force magnitude scale shown here, taken to be $2 \times 10^{10} \mathrm{~N}$, is used to estimate a rough stress magnitude scale to be applied over the area of the vertical face of a $15 \mathrm{~km}$ rift necessary to break off the tip of the Drygalski Ice Tongue to produce C25. This rough magnitude is $4 \times 10^{3} \mathrm{~Pa}$, and can be used as a rule-of-thumb when considering stresses adequate to induce iceberg calving from ice tongues. 


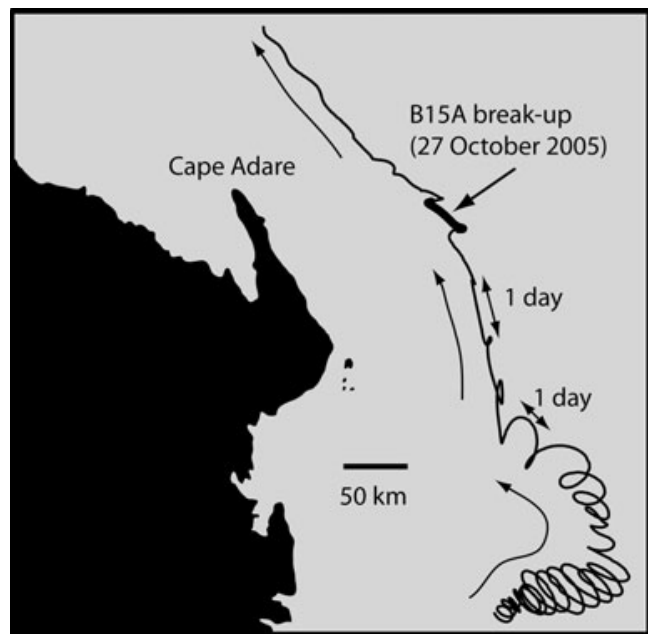

Fig. 16. Trajectory of the center of area of B15A during the time surrounding the break-up of B15A (from 1 October 2005 to 1 November 2005). The segment during the day of break-up (27 October 2005) is highlighted in bold. The coast immediately west of the trajectory on the day of break-up is Cape Adare. To gauge the passage of time along the trajectory, note that the large loops of the trajectory as B15A approached Cape Adare represent the iceberg's motion induced by topographic vorticity waves excited by the diurnal tide (MacAyeal, 1984; Padman and others, 2003). The iceberg takes $\sim 24$ hours to perform each loop.

directed roughly parallel to the local contours of bathymetry. While the velocity of the iceberg associated with these linear motions was still large, they quickly subdued as the iceberg moved west and the neap-tide phase approached. Of particular note, the north-south velocity, a component approximately perpendicular to the bathymetric contours of the area, appears to have become constrained, i.e. to be non-negative during 27 October, the day of break-up. This suggests interaction with the seabed and the influence of invisible forces of constraint associated with static rigid bodies mentioned previously. From the perspective provided by the velocity, the temporal coincidence of the iceberg's grounding and its break-up motivates seabed interaction as a cause of break-up (Martin and others, 2007).

Forces associated with the iceberg's motion over the time period display much of the same behavior as the velocities (Fig. 18). To facilitate comparison of forces acting before and after the break-up, the net mass of B15A was not changed in the least-squares computation described above. (Had it been reduced by a factor of 2 , an additional reduction of apparent forces would have been apparent following the day of breakup in Figure 18.) Prior to the day of break-up, the force magnitudes and components are large (in excess of $60 \times$ $10^{10} \mathrm{~N}$ ) and predominantly diurnal, suggesting the influence of tidal forcing. The forces began to subdue on the day of break-up and reduce to a much smaller magnitude as the neap phase of the tide set in.

\section{STRESS SCALES OF ICEBERG GROUNDING, CALVING AND BREAK-UP}

The variety of force magnitudes and patterns observed in the above three episodes of notable iceberg behavior is difficult to characterize in a simple fashion useful as a general guide for understanding iceberg calving and break-up. To address this difficulty in as simple a manner as possible, we compute stress scales for the three episodes by dividing the maximum force magnitude derived on the day in question (e.g. the maximum $|\mathbf{F}|$ on the day B15A broke up) by an estimated area over which the forces act (e.g. the area of ice broken to create new rifts) to arrive at a stress scale representative of the state of stress within the appropriate system at the time of the event. When B15A struck C16 to force C16 to move across the seabed, as seen in the March 2002 time frame of Figure 12 , the maximum force magnitude is $\sim 20 \times 10^{10} \mathrm{~N}$. Assuming the area of $\mathrm{C} 16$ to be $7 \times 10^{8} \mathrm{~m}^{2}$, and that $10 \%$ of this area was in contact with the shoal on which the iceberg was grounded, the stress scale of basal strength resisting iceberg movement is $\sim 3 \times 10^{3} \mathrm{~Pa}$. This basal-stress scale is consistent with basal stresses on various ice streams feeding the Ross Ice Shelf, and suggests that the nature of contact between the base of an iceberg and the seabed is not significantly different to basal conditions beneath glaciers and ice streams.

The stress state during calving of $\mathrm{C} 19$ as a result of the collision between B15A and the Ross Ice Shelf is a little more difficult to assess in a simple manner, because B15A was motionless during the actual calving (and static force balance was responsible for creating the state of stress in the ice shelf and iceberg). The magnitude of force, $|\mathbf{F}|$, in the days after C19 calved, displayed in Figure 12 , is $\sim 5 \times$ $10^{10} \mathrm{~N}$ (the magnitude quickly ramps up in the days following calving, primarily as a result of the onset of the spring tide; so we choose a low value). The area of C19's detachment rift that was unbroken at the time of calving is estimated to be $\sim 8 \times 10^{6} \mathrm{~m}^{2}$. We assume that the length of the new detachment rift needed to calve C19 is $40 \mathrm{~km}$ (Joughin and MacAyeal, 2005), and that the average ice thickness along this rift is $200 \mathrm{~m}$ (Bentley and others, 1979). This implies a stress of $\sim 6 \times 10^{3} \mathrm{~Pa}$ on the rift at the time C19 calved. The result of this simple scale analysis, however, could be misleading. The force transmitted by B15A's contact with the Ross Ice Shelf could be amplified by the mechanical advantage of the lever action associated with B15A's rotation about a fulcrum provided by contact with C16.

Another opportunity to measure the stress state of calving is provided by C16's collision with the Drygalski Ice Tongue that produced iceberg C25 when the tip of the ice tongue broke off (Fig. 13). The magnitude of force, $|\mathbf{F}|$, in the day following the calving of $\mathrm{C} 25$, as measured by the acceleration of $\mathrm{C} 25$, is $\sim 2 \times 10^{10} \mathrm{~N}$. Assuming the length of the detachment rift necessary to produce C25 is $15 \mathrm{~km}$, and the ice thickness is $300 \mathrm{~m}$, the area of the new detachment rift needed to calve C25 is estimated to be $4.5 \times 10^{6} \mathrm{~m}^{2}$. Division of the force magnitude by this area gives a stress scale of $\sim 4 \times 10^{3} \mathrm{~Pa}$. This scale is consistent with the result from simple analysis of the detachment of C19.

A final stress scale to be estimated is that which was active during the break-up of B15A off Cape Adare (Fig. 16). Estimating $|\mathbf{F}|$ to be $3 \times 10^{11} \mathrm{~N}$ (Fig. 18) and assuming that $200 \mathrm{~km}$ of new detachment rift through an ice thickness of $250 \mathrm{~m}$ is required to produce the observed break-up pattern of the iceberg (see MacAyeal and others, 2006 for images of B15A following its break-up on 27 October 2005), the stress scale associated with break-up is estimated to be $\sim 6 \times 10^{3} \mathrm{~Pa}$. Again, this scale is consistent with the estimates developed above for the creation of iceberg detachment rifts during calving. 

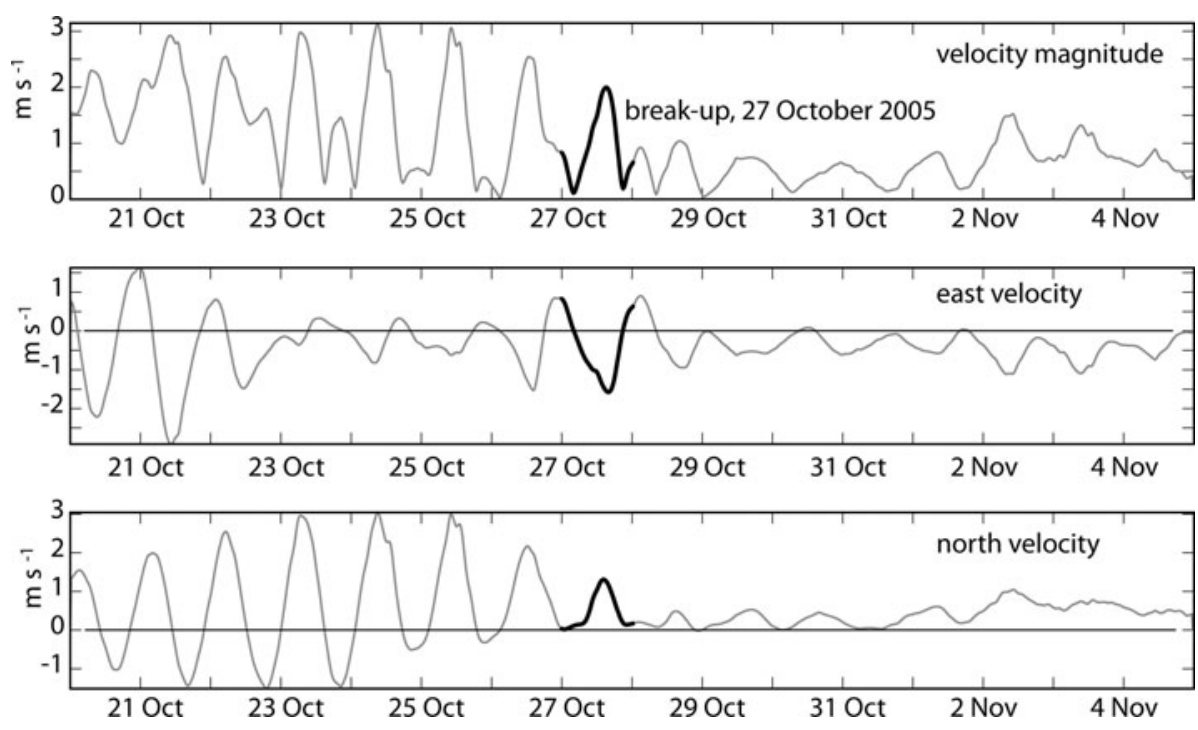

Fig. 17. Velocity of B15A surrounding the time of its break-up on 27 October 2005. The day of break-up is highlighted in bold. The northsouth velocity appears to be constrained to be non-negative after 27 October 2005, and this may reflect grounding of the iceberg in shallow waters near Cape Adare (Martin and others, 2007). The correspondence between time on the graphs shown above and the trajectory shown in Figure 16 can be made by associating each loop in the trajectory with one 24 hour period.

The simplicity of the method used to obtain the above crude estimates of stress scales associated with iceberg calving and grounding does not lend itself to assessing uncertainty in the estimates so derived. The consistency of the stress scales required to create new detachment rifts (leading to iceberg calving or break-up) suggests that a stress scale of order $10^{4} \mathrm{~Pa}$ is necessary to break floating ice. This scale is smaller than the scale conventionally thought (e.g. $10^{5} \mathrm{~Pa}$ ) to initiate the brittle failure of ice, but this undoubtedly reflects the fact that the broadly distributed forces estimated in the above analysis would be focused into smaller areas around the active tips of rupturing detachment rifts.
That the broadly distributed stress scale necessary for rift rupture estimated here is greater than the stress scale estimated above for iceberg sliding over the seabed (i.e. C16 being pushed across its grounding shoal) provides a simple explanation for why icebergs can remain stationary following grounding. If the stress scale necessary to break up the iceberg were less than the stress scale produced by basal contact with seabed shoals, icebergs would simply fragment after grounding, and pieces not individually grounded would continue to drift. If the crude stress-scale estimates provided here are meaningful, then insight into another aspect of glaciological behavior is provided. Resistance of seaward ice flow provided to ice streams that ice shelves
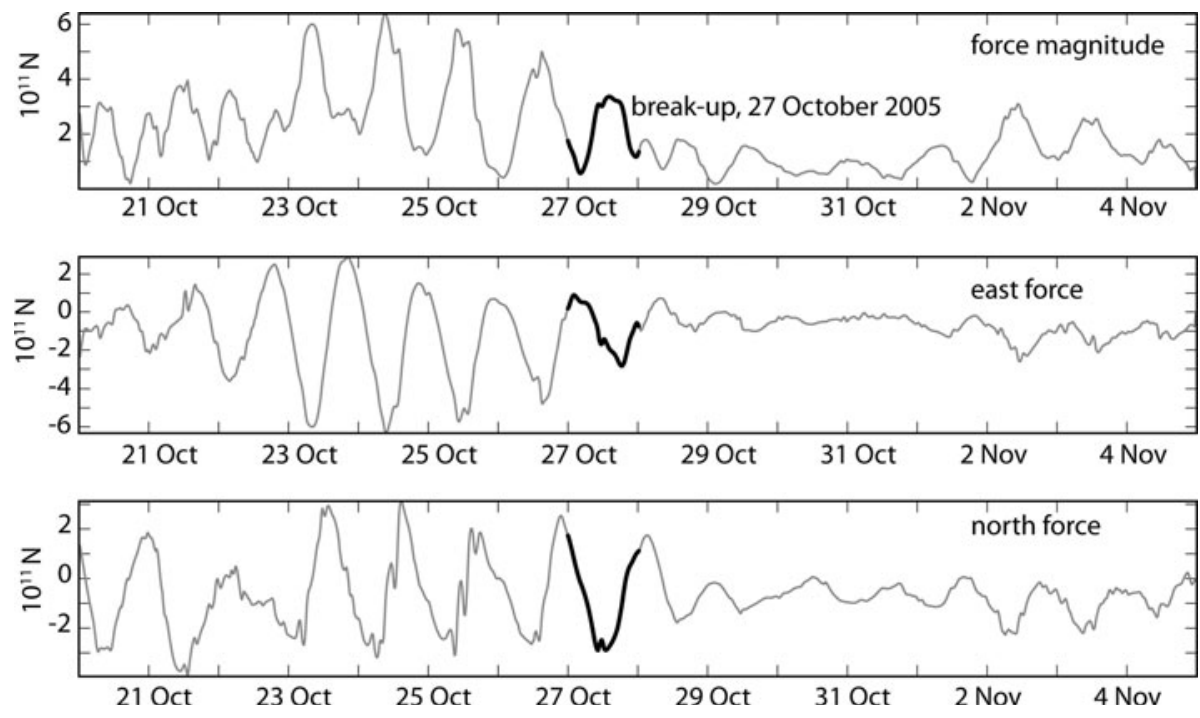

Fig. 18. Force magnitude and components during the break-up of B15A on 27 October 2005. The day of break-up is highlighted in bold. The force magnitude scale shown here, taken to be $3 \times 10^{11} \mathrm{~N}$, is used to estimate a rough stress magnitude scale to be applied over the area of the vertical face of a $200 \mathrm{~km}$ rift necessary to break the iceberg into several pieces. This rough magnitude is $6 \times 10^{3} \mathrm{~Pa}$, and can be used as a rule-of-thumb when considering stresses adequate to induce iceberg break-up. 
buttress relies, in large part, on the grounding of ice shelves on the seabed to form ice rises and ice rumples. The fact that ice shelves are able to ground at all, without producing rifts that would disintegrate the ice shelf, may be another consequence of the result found here that the stress scale produced by grounding is smaller than that required to rupture new rifts.

\section{CONCLUSIONS}

Analysis of the kinematics and dynamics of iceberg drift reveals the basic mechanisms of an extraordinary 7 year period when large tabular icebergs were variously adrift and grounded in the southwestern Ross Sea. Iceberg B15A, the largest of the icebergs, was generally mobile during the 2001-05 period when it was located in the immediate vicinity of Ross Island. During this time, the iceberg's motion was strongly constrained by boundaries imposed by its surroundings. While not a perfect analogy, the motion of B15A during this period is analogous to that of a key inserted into a loosely fitting keyhole. The iceberg rattled about the limited region of a keyhole defined by Ross Island, the Ross Ice Shelf and grounded iceberg C16; however, the movement was not sufficient to successfully withdraw the iceberg from the keyhole. During this time of confinement, B15A collided repeatedly with $\mathrm{C} 16$, sometimes forcing C16 to move over the grounding points which constrained it. Additionally, B15A collided with Ross Island, causing difficulties for penguin colonies there, and with the Ross Ice Shelf, contributing to the calving of C19, an iceberg of similar dimensions to B15A.

Forces associated with iceberg motions are dominated by ocean tide effects, as expected from the dominance of tidal periodicity in the overall motion of the icebergs. The forces are sufficiently irregular to indicate that three conditions are active. First is the presence of significant non-tidal ocean, sea-ice and atmospheric forces that contribute to the irregularity of the forcing time series. Quantification of these non-tidal forces is beyond the scope of this study, because our observations do not provide information about ocean currents, sea-surface topography, sea-ice conditions or winds over the region surrounding the icebergs. Second is the effect of collision among the icebergs and between them and surrounding coastal features. Again, it is difficult to quantify the contribution of collisions to the force balance, due to the nature of the observations. What is clear, however, is the fact that sharp, impulsive forces do not necessarily arise from collisions, and this is probably due to the fact that failure of the iceberg edges (creation of push mounds and other features seen in Fig. 2) tends to soften and prolong the collision process, allowing slow decelerations of convergent iceberg movements. The third condition that modifies iceberg forces is due to the assumed rigid-body rheology of our force-balance treatment. When icebergs lock into constrained positions preventing further motion, forces resulting from static balance are invisible to the observational methodologies we employed (GPS measurement of iceberg motion). These static forces give rise to the elastic and brittle behavior associated with iceberg calving (in the case of B15A's collision with the Ross Ice Shelf spawning C19) and iceberg break-up (in the case of B15A's grounding along seabed shoals near Cape Adare).

Possibly the least well anticipated of the results presented here is that iceberg collisions with landfast glacial ice that spawn new icebergs (the Ross Ice Shelf, in the case of C19, and the Drygalski Ice Tongue, in the case of C25) tend to involve static force balances as opposed to forces arising from sudden deceleration of the impacting iceberg. In the case of the calving of C19, B15A was motionless for several days prior to the release of C19. B15A pressed against the Ross Ice Shelf like a long lever with C16 acting as a fulcrum, but was otherwise static. Once C19 released from the ice shelf, B15A's southern end immediately began to move east, reflecting the fact that the previous static force balance was relieved by subsequent acceleration of both B15A and C19. The collision between $\mathrm{C} 16$ and the Drygalski Ice Tongue producing C25, and the break-up of B15A associated with a period of grounding near Cape Adare, also show evidence of static force balance; however, in these examples, the icebergs were not absolutely motionless, but rather were constrained to be motionless in one direction only.

From the oceanographic standpoint, the results presented here suggest that large tabular icebergs are not simply free tracers of ocean current and wind forcing. The sheer size of the icebergs, and the awkward coastal geometries they must negotiate to make progress in their drift, constrain them to react unpredictably and irregularly. Once these icebergs get into deep water off the continental slope, their trajectories may become simplified and begin to trace ocean currents and winds. This remains to be determined, once the icebergs studied here reach the Antarctic Circumpolar Current. While on the continental shelf, however, their motions are largely irregular and unpredictable.

This irregularity has important implications. Entrapment of icebergs within the near-coastal region, if this process can be generalized to other places and times, could have important consequences on the oceanic and glaciological environment of the world ocean, and could additionally have significant impact on coastal ecology and sea-surface productivity. Movement of the $>3000 \mathrm{~km}^{2}$ iceberg B15 from the Ross Sea to the open ocean, for example, has been spread over many years ( 7 years so far) due to the fact that the original iceberg broke into several large pieces many of which (notably B15A, B15J and B15K) became trapped within a limited region of Ross Island at the western end of the Ross Ice Shelf ice front. The effect of B15's original ice volume (estimated to be $\sim 2000 \mathrm{~km}^{3}$ ) on thermohaline structure of the open ocean beyond Antarctica is thus distributed in time rather than impulsive, as would be the case if the coastal processes documented had not led to the iceberg's fragmentation and entrapment of the various pieces. If coastal trapping also influences icebergs discharged into parts of the world ocean where overturning circulation is sensitive to freshwater flux (e.g. the North Atlantic during glacial times (Ganopolski and Rahmstorf, 2001; Hemming, 2004)), coastal processes could conceivably mitigate the circulation knock-down effect associated with ice-sheet discharge.

Important glaciological effects may also be associated with coastal entrapment. In response to the long, multi-year presence of B15A near Ross Island, for example, thick shorefast multi-year sea ice became pervasive along the Victoria Land coast, between McMurdo Sound and the Drygalski Ice Tongue (Fig. 1) where open water was typically achieved on a yearly basis (Brunt and others, 2006). Had B15A been trapped in the region permanently, glacier-tongue advance and coalescence of shore-fast multi-year sea ice may have produced new, permanent ice-shelf cover. 
Icebergs entrapped in the coastal environment also impact coastal ecology (e.g. Arrigo and others, 2002; Smith and others, 2007). Shifts in penguin foraging and breeding behavior (Ainley and others, 2004, 2006) were reported as a result of B15A's long presence near Ross Island (see Fig. 3). Episodic catastrophes associated with blockage of access to breeding colonies of these strongly philopatric (returning to same location for breeding) animals may thus contribute to their genetic diversity and macro-evolutional fitness (Shepherd and others, 2005).

\section{ACKNOWLEDGEMENTS}

Financial and logistical support was provided by the US National Science Foundation (NSF) under grants OPP0229546 and OPP-0230028. We thank B. Kerman for field assistance during the 2001 season. The manuscript was substantially improved as a result of reviews by two anonymous referees and S. Jacobs. We also thank the numerous people of the various United States Antarctic Program organizations (Raython Polar Services Co., Petroleum Helicopters Inc., Kenn Borek Air Ltd and ANGNY) who helped us in the field. We thank M. Lazzara, S. Knuth, L. Keller and G. Weidner of the Antarctic Meteorological Research Center of the University of Wisconsin for assistance with equipment design, satellite image acquisition and for archiving data. The photograph displayed in Figure 7 is a reduced, black-and-white rendition of the original photograph on display at http://www.yannarthusbertrand.com. As part of the agreement to use this photograph, we mention that the photographs of Earth from above (on display at http:// www.yannarthusbertrand.com) invite reflection on the future of Earth and its inhabitants, and remind us that each and everyone is responsible for the future of Earth.

\section{REFERENCES}

Ainley, D.G. and 8 others. 2004. Geographic structure of Adélie penguin populations: overlap in colony-specific foraging areas. Ecol. Monogr., 74(1), 159-178.

Ainley, D.G., G. Ballard and K.M. Dugger. 2006. Competition among penguins and cetaceans reveals trophic cascades in the Western Ross Sea, Antarctica. Ecology, 87(8), 2080-2093.

Arrigo, K.R., G.L. van Dijken, D.G. Ainley, M.A. Fahnestock and T. Markus. 2002. Ecological impact of a large Antarctic iceberg. Geophys. Res. Lett., 29(7), 81-84.

Bentley, C.R. and M.B. Giovinetto. 1991. Mass balance of Antarctica and sea level change. In Weller, G., C.L. Wilson and B.A.B. Severin, eds. Proceedings of the International Conference on the Role of the Polar Regions in Global Change 11-15 June 1990, Fairbanks, Alaska, USA. Fairbanks, AK, University of Alaska. Geophysical Institute, 481-488.

Bentley, C.R., J.W. Clough, K.C. Jezek and S. Shabtaie. 1979. Icethickness patterns and the dynamics of the Ross Ice Shelf, Antarctica. J. Glaciol., 24(90), 287-294.

Bigg, G.R., M.R. Wadley, D.P. Stevens and J.A. Johnson. 1997. Modelling the dynamics and thermodynamics of icebergs. Cold Reg. Sci. Technol., 26(2), 113-135.

Brunt, K.M., O. Sergienko and D.R. MacAyeal. 2006. Observations of unusual fast-ice conditions in the southwest Ross Sea, Antarctica: preliminary analysis of iceberg and storminess effects. Ann. Glaciol., 44, 183-187.

Davey, F.J. 2004. Ross Sea bathymetry, $1: 2,000,000$, version 1.0. Lower Hutt, Institute of Geological and Nuclear Sciences Ltd. (Geophysical map 16.)
Frezzotti, M. and M.C.G. Mabin. 1994. 20th century behaviour of Drygalski Ice Tongue, Ross Sea, Antarctica. Ann. Glaciol., 20, 397-400.

Ganopolski, A. and S. Rahmstorf. 2001. Rapid changes of glacial climate simulated in a coupled climate model. Nature, 409(6817), 153-158.

Glaciological Society. 1962. Early discoverers XVI. The origin of tabular icebergs in the Southern Ocean. J. Glaciol., 4(31), 126-127.

Gladstone, R.M., G.R. Bigg and K.W. Nicholls. 2001. Iceberg trajectory modeling and meltwater injection in the Southern Ocean. J. Geophys. Res., 106(C9), 19,903-19,916.

Hemming, S.R. 2004. Heinrich events: massive late Pleistocene detritus layers of the North Atlantic and their global climate imprint. Rev. Geophys., 42(1), RG1005. (10.1029/ 2003RG000128.)

Herdman, H.F.P. 1959. Early discoverers XII. Some notes on sea ice observed by Captain James Cook, RN, during his circumnavigation of Antarctica, 1772-75. J. Glaciol., 3(26), 534-541.

Jacka, T.H. and A.B. Giles. 2007. Antarctic iceberg distribution and dissolution from ship-based observations. J. Glaciol., 53(182), 341-356.

Jacobs, S.S., H.H. Hellmer, C.S.M. Doake, A. Jenkins and R.M. Frolich. 1992. Melting of ice shelves and the mass balance of Antarctica. J. Glaciol., 38(130), 375-387.

Joughin, I. and D.R. MacAyeal. 2005. Calving of large tabular icebergs from ice shelf rift systems. Geophys. Res. Lett., 32(2), L02501. (10.1029/2004GL020978.)

Lazzara, M.A., K.C. Jezek, T.A. Scambos, D.R. MacAyeal and C.J. van der Veen. 1999. On the recent calving of icebergs from the Ross Ice Shelf. Polar Geogr., 23(3), 201-212.

Lichey, C. and H.H. Hellmer. 2001. Modeling giant-iceberg drift under the influence of sea ice in the Weddell Sea, Antarctica. J. Glaciol., 47(158), 452-460.

Long, D.G., J. Ballantyne and C. Bertoia. 2002. Is the number of Antarctic icebergs really increasing? Eos, 83(42), 469.

MacAyeal, D.R. 1984. Numerical simulations of the Ross Sea tides. J. Geophys. Res., 89(C1), 607-615.

MacAyeal, D.R. and 13 others. 2006. Transoceanic wave propagation links iceberg calving margins of Antarctica with storms in tropics and Northern Hemisphere. Geophys. Res. Lett., 33(17), L17502. (10.1029/2006GL027235.)

Martin, S., R.S. Drucker and R. Kwok. 2007. Winter properties of the western Ross Sea polynyas during 1991-2002 and their relation to the B-15 and C-19 iceberg events of 2000 and 2002. J. Mar. Syst., 68(1-2), 201-214.

Okal, M.H. 2005. Characteristics of iceberg collisions. (MS thesis, University of Chicago.)

Padman, L., S. Erofeeva and I. Joughin. 2003. Tides of the Ross Sea and Ross Ice Shelf cavity. Antarct. Sci., 15(1), 31-40.

Parmiggiani, F. and C. Fragiacomo. 2005. Cover: the calving event of the Drygalski Ice Tongue of February 2005. Int. J. Remote Sensing, 26(21), 4633-4638.

Peters, M.E., D.D. Blankenship, D.E. Smith, J.W. Holt and S.D. Kempf. 2007. The distribution and classification of bottom crevasses from radar sounding of a large tabular iceberg. IEEE Geosci. Remote Sens. Lett., 4(1), 142-146.

Rignot, E. and R.H. Thomas. 2002. Mass balance of polar ice sheets. Science, 297(5586), 1502-1506.

Robertson, R., L. Padman and G.D. Egbert. 1998. Tides in the Weddell Sea. In Jacobs, S.S. and R.F. Weiss, eds. Ocean, ice and atmosphere: interactions at the Antarctic continental margin. Washington, DC, American Geophysical Union, 341-369. (Antarctic Research Series 75.)

Shabtaie, S. and C.R. Bentley. 1982. Tabular icebergs: implications from geophysical studies of ice shelves. J. Glaciol., 28(100), 413-430.

Shepherd, L.D. and 7 others. 2005. Microevolution and megaicebergs in the Antarctic. Proc. Nat. Acad. Sci. USA (PNAS), 102(46), 16,717-16,722. 
Silva, T.A.M., G.R. Bigg and K.W. Nicholls. 2006. Contribution of giant icebergs to the Southern Ocean freshwater flux. J. Geophys. Res., 111(C3), C03004. (10.1029/2004JC002843.) Smith, K.L., Jr, B.H. Robison, J.J. Helly, R.S. Kaufmann, H.A. Ruhl and T.J. Shaw. 2007. Free-drifting icebergs: hot spots of chemical and biological enrichment in the Weddell Sea. Science, 317(5837), 478-482.

Swithinbank, C., P. McClain and P. Little. 1977. Drift tracks of Antarctic icebergs. Polar Rec., 18(116), 495-501.

Vaughan, D.G., J.L. Bamber, M.B. Giovinetto, J. Russell and A.P.R. Cooper. 1999. Reassessment of net surface mass balance in Antarctica. J. Climate, 12(4), 933-946.
Wunsch, C. 1988. Transient tracers as a problem in control theory. J. Geophys. Res., 93(C7), 8099-8110.

Young, N.W. 1998. Antarctic iceberg drift and ocean currents derived from scatterometer image series. In ESA-Spec. Publ.. 424, 125-132.

Young, N. 2002a. Another massive iceberg is born. Austral. Antarct. Mag. 4, 40.

Young, N. 2002b. More of those big bergs: where are they now? Austral. Antarct. Mag. 3, 36-37.

Young, N. 2005. Massive icebergs on the move. Austral. Antarct. Mag. 9, 17.

MS received 19 June 2007 and accepted in revised form 19 November 2007 